\title{
Review of Connections for Engineered Bamboo Structures
}

\author{
Chaokun Hong ${ }^{1 \mathrm{a}, 1 \mathrm{~b}}$, Haitao $\mathrm{Li}^{1 \mathrm{a}, 1 \mathrm{~b}^{*}}$, Zhenhua Xiong ${ }^{2}$, Rodolfo Lorenzo ${ }^{3}$, Ileana Corbi ${ }^{4}$, Ottavia \\ Corbi ${ }^{4}$, Dongdong Wei ${ }^{5}$, Conggan Yuan ${ }^{5}$, Dong Yang ${ }^{1 a, 1 b}$, Huizhong Zhang ${ }^{1 a, 1 b}$ \\ 1a College of Civil Engineering, Nanjing Forestry University, Nanjing 210037, China; ${ }^{\text {b }}$ Joint International Research Laboratory \\ of Bio-composite Building Materials and Structures, Nanjing Forestry University, Nanjing 210037, China \\ ${ }^{2}$ Ganzhou Sentai bamboo company LTD, Ganzhou 341001, China. \\ ${ }^{3}$ University College London, London WC1E 6BT, UK. \\ ${ }^{4}$ University of Naples Federico II, Via Claudio 21,80133 Naples, Italy. \\ 5 Jiangxi Feiyu Bamboo Stock Co. LTD, Fengxin 330700, China \\ *Corresponding author: Haitao LI, Professor, E-mail: lhaitao1982@126.com
}

\begin{abstract}
Bamboo is a green building material that is environmentally friendly and has great development value. However, the limited mechanical properties and heterogeneous dimensions of natural bamboo poles curb the application of bamboo in building structures. A transverse section of engineered bamboo is regular and compact, and its mechanical properties are stable, which can meet the requirements for physical and mechanical properties of materials in modern building structures. Though application of engineered bamboo has just started, it is of great significance to study the connection performance and corresponding influence factors for popularization and application of modern bamboo structures. This paper is focused on a review of research progress for connections in engineered bamboo structures. Firstly, a study on embedding strength and the performance of bolted joints is presented, including calculation methods described with a proposal for future development of standards suitable for the characteristics of engineered bamboo materials. Secondly, research on carpentry joints is introduced, namely tenonmortise joints, nail joints and truss plate joints. Finally, some engineering examples are briefly introduced. This work can provide a reference for further research on connections in engineered bamboo structures.
\end{abstract}

Keywords: Engineered bamboo; connection; connection calculation; embedding strength

\section{Introduction}

Bamboo is one of the few renewable resources in the world and an important non-wood product which can be used in many fields of application especially in residential buildings [1]. Bamboo has been used as building materials since ancient times and has a history of thousands of years. In ancient times, bamboo was used to build houses because of its relatively high strength and excellent flexibility. In modern times, people choose bamboo as building materials for the pursuit of natural texture as well as low-carbon environmental protection characteristics. In recent years, with the global development of economy and society, the progress of science and technology, and the promotion of national policies, bamboo structures have the potential to coexist with the ecological environment during their whole life cycle as a future development direction.

The connection of natural bamboo poles in buildings has always been a major difficulty in the application of bamboo [2]. Because of the complex form of natural bamboo joints, the construction process of natural bamboo joints is always confronted with problems such as inconvenience and poor reliability of connection, which severely hinders the development of natural bamboo buildings. In addition to the performance of the joints, the hollow and thin-walled characteristics of the raw bamboo curb the application as well [3]. Although some research has been carried out on the improvement of basic materials, it still cannot solve the problem perfectly [4], [5], [6]. However, the appearance of engineered bamboo can effectively solve these problems.

Typical forms of engineered bamboo used in building structures are laminated bamboo lumber (LBL), 
parallel bamboo strand lumber (PBSL) and GluBam (Fig. 1). Laminated bamboo lumber [7], [8], [9], [10], [11], [12], [13], [14], is made by gluing the thin flat laminates with a certain width and thickness together. The bamboo culm is disassembled into thin flat laminates firstly. After being dried to a moisture content of $8 \% \sim 12 \%$ and removed the inner skin and outer skin, the flat laminates can be glued together to form laminated bamboo lumber under hot pressing (or cold pressing). The cross-section size and length of LBL can be flexibly controlled by the current manufacturing technology, which can solve the limitation of member size and enhance dimensional consistency, strength and uniformity. When a larger cross-section is required, only the cold pressing process can be used. Because the hot pressing process cannot ensure that bamboo laminates are heated uniformly. If the temperature or the hot pressing time is increased, the degree of carbonization of bamboo laminates is uneven, and the outer laminates are easy to crack. However, the cold pressing process also has the problem of time-consuming. GluBam [15], [16], [17], is a composite material with a special arrangement of fibers and processed by special technology. The greatest advantage of GluBam is that it can determine the direction of layers and the ratio of longitudinal and transverse fibers in the interior according to the structural requirements. When making beam and column components, increasing the ratio of longitudinal and transverse fibers as much as possible is beneficial to improving the strength of GluBam and the utilization ratio of materials. However, an unreasonable ratio may lead to a larger deformation of GluBam panel and weaker transverse properties, which will cause adverse effects on processing and construction. Therefore, under the existing technical conditions, the most applied fiber ratio is $4: 1$, and the thickness of GluBam panel is $30 \mathrm{~mm}$ [16]. This type of panel has good longitudinal mechanical properties, and a certain amount of fibers in the transverse direction can ensure the integrity of materials and components in the secondary direction. Parallel bamboo strand lumber [18], [19], [20], [21], [22], [23], [24], [25], [26], [27], [28], [29], is made by gluing the bamboo filament bundles together. The bamboo culm is disassembled into long bamboo strands firstly. After being dried and charred, the strands can be put into the molds and pressed into parallel bamboo strand lumber under hot pressing (or cold pressing). PBSL material and its texture are similar to hardwood, so it is welcomed by consumers. However, the disadvantage of this material is that the amount of adhesive is large, and the adhesive cannot be characterized by low cost and high bonding strength at the same time [19].

In contrast to timber, usable bamboo can be harvested in 3-4 years, and the mechanical properties of engineered bamboo compare favorably with those of timber [30]. Compared with natural bamboo, the mechanical properties of engineered bamboo are uniform and stable, but its physical properties change greatly. The transverse section is regular and compact, and the dimension is easy to be unified, so the rapid and mass production of steel member joints can be realized. At present, there are many studies on connections of timber structures, but relatively few on modern engineered bamboo structures. By studying the existing literature, it is found that the research of engineered bamboo connection can be roughly divided into bolted joints, tenon-mortise joints, nail/screw joints, truss plate joints. This paper summarizes the research progress of engineered bamboo joints, in order to provide a reference for the research and application of connection in engineered bamboo structures.

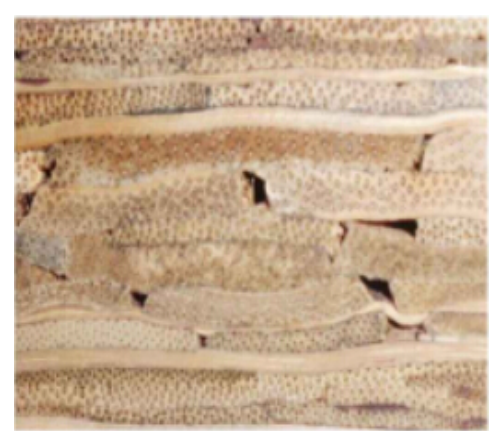

(a) GluBam

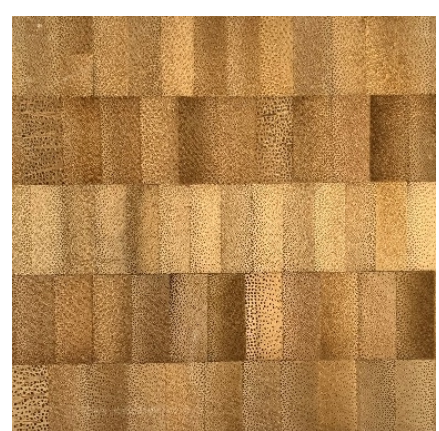

(b) LBL

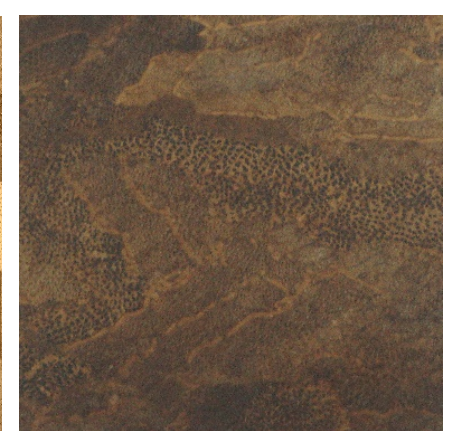

(c) PBSL

Figure 1: Common cross section forms of engineered bamboo (a, [17]; b, c reproduced with permission of Dong Yang) 


\section{Bolted Joint}

Bolted joints are widely used in timber structures [31], [32] and have the advantages of simplicity, reliability and convenience, which can fully exploit the mechanical properties of the connected materials. There are many kinds of bolted joints, which can be classified into three types according to the stress conditions (Fig. 2): single shear connection, double shear connection, and multi shear connection. According to the position of steel plate, they can be classified into two types: bolted joint with steel splints and bolted joint with embedded steel plates. They can also be classified according to whether the metal plate is used or not [33].
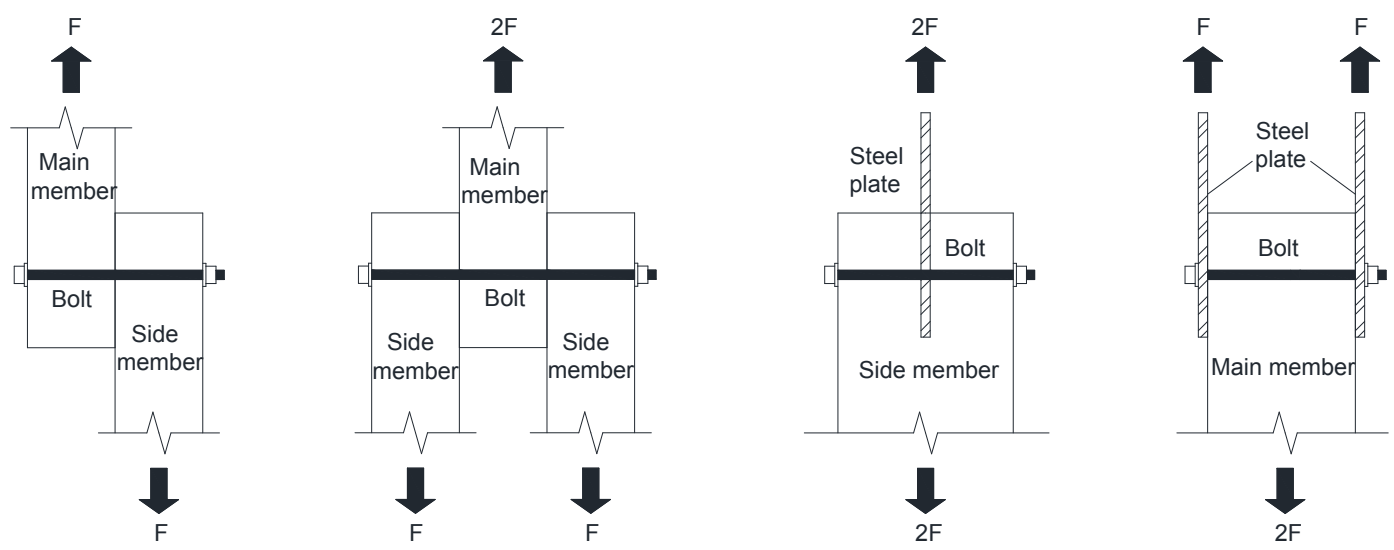

Figure 2: Schematic of single shear and double shear connection

\subsection{Failure Mode of Bolted Connections}

If there is no restriction on the construction of bolted joints, the joints may be damaged in many ways. In the study of bolted joints in timber structures, there are four main failure modes of connections (Fig. 3):
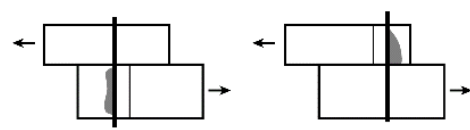

Mode Im

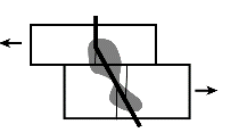

Mode IIIm

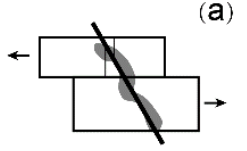

Mode II

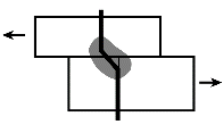

Mode IV

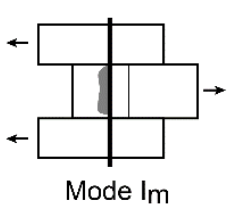

(Not applicable)

Mode IIIm

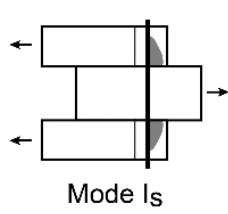

(Not applicable)

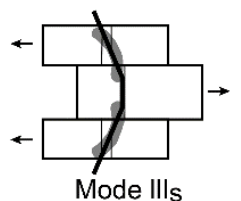

Mode II

(b)

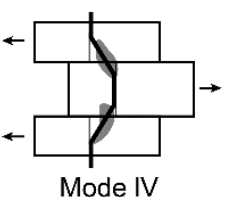

(a) Four failure modes of single shear connections (b) Four failure modes of double shear connections

Figure 3: Failure modes of bolted connections [34]

The failure mode $\mathrm{I}$ is determined by the strength of either the main $\left(\mathrm{I}_{\mathrm{m}}\right)$ or side $\left(\mathrm{I}_{\mathrm{s}}\right)$ member, which belongs to wood bearing failure. When the connector is damaged, the main or side member reaches the ultimate strength and bolts remain intact. The failure mode II is a rotation of the bolt in the connector without bending. The failure mode III and IV are mixed failure modes, which are a combination of wood bearing failure and one or several plastic hinge formations in the bolt. When the connector is damaged, the bolt reaches the ultimate bearing capacity and forms plastic hinges, while the member reaches the ultimate strength as 
well.

\subsection{Study on Embedding Strength}

As early as 1932, Trayer [35] conducted axial compression tests on bolted joints. It was found that the performance of bolted joints was affected by the interaction between bolt bending and wood crushing. In 1949, Johansen [36] put forward the European Yield Model (EYM) to predict the strength of bolted joints, which considered that the strength of bolted joints was mainly affected by two factors: the flexural strength of bolts and the embedding strength of wood. McLain et al. [37] and Soltis et al. [38] validated the applicability of EYM and perfected it to determine the yield strength of the connector within a specific precision range. In 1991, yield theory was introduced into the design code of timber structures in the United States to substitute the previous empirical design method. The theoretical calculation formula in the design code is closely related to the embedding strength of wood. Therefore, accurate determination of the embedding strength is the key to obtain the bearing capacity of bolted connections. Scholars have researched the embedding strength of engineered bamboo (Fig. 4-5).
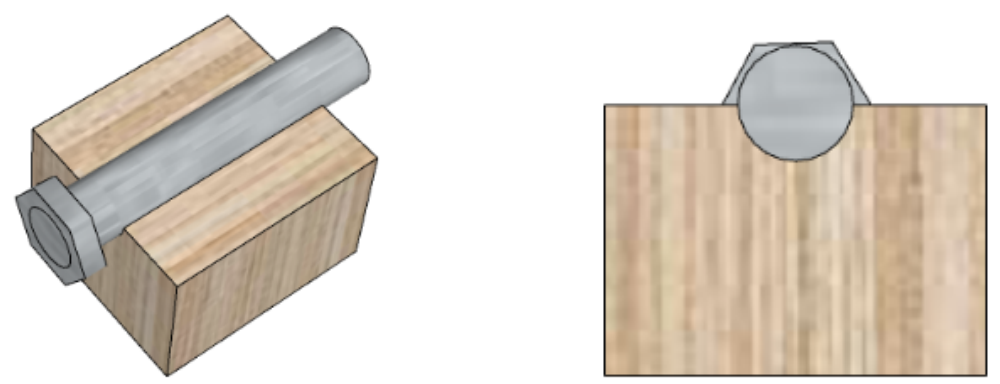

Figure 4: Schematic of half-hole test specimens
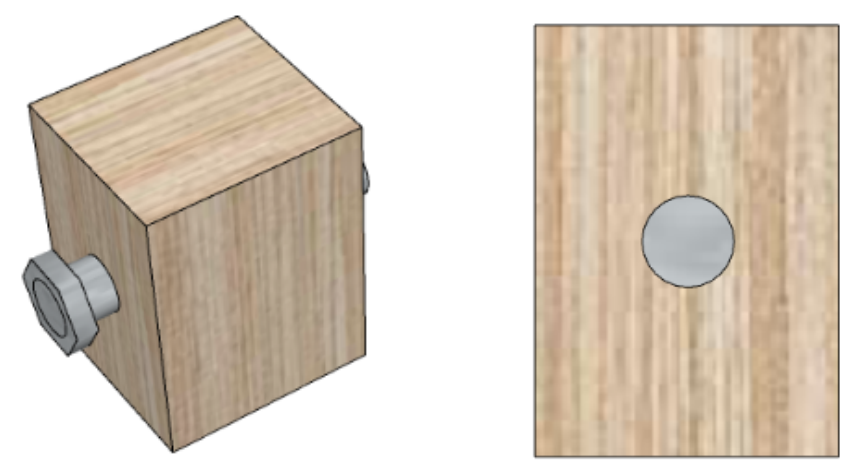

Figure 5: Schematic of full-hole test specimens

Eratodi et al. [39] took the specific gravity G of material as the influencing factor and carried out experimental research and finite element analysis on the embedding strength of LBL. The results showed that the embedding strength parallel to the grain direction (parallel loading to grain radial, parallel loading to grain tangential) of the specimen was significantly higher than that perpendicular to the grain direction, which was found to be 54.13 MPa, 48.14 MPa and 30.27 MPa, respectively. Ramirez et al. [40] studied the dowel-bearing strength of LBL with the diameter of bolts and the direction of loading as the influencing factors. It was found that similar to wood, the dowel-bearing strength decreased as the fastener diameter increased because of the volume effect under the fastener hole, and the simulations indicated that this property depended on the specimen's width-to-fastener diameter ratio as well. Gonzalez [41] found that the direction of grain and the diameter of prefabricated holes did not have an effect on the embedding strength 
of bamboo mat board and bamboo strip board, and the density of material was an essential factor to determine the strength. Based on the European Standard 383 test method, the embedding strength of bamboo mat board and bamboo strip board were $92.5 \mathrm{MPa}$ and $86.2 \mathrm{MPa}$ on average respectively.

Li [42] comprehensively considered the influence of sample size, bolt diameter, moisture content, grain direction and loading direction, and carried out experimental research on the embedding strength of PBSL. The results showed that the sample size had no significant influence on the bearing strength under the premise of meeting the minimum requirements of size; with the increase of bolt diameter, the bearing strength decreased; with the increase of grain angle from $0^{\circ}$ to $90^{\circ}$, the strength decreased firstly and then increased. The failure mode changed from a mixed failure of splitting in the parallel to the grain direction and crushing on the ends of sample, to a mixed failure of groove crushing and whole sample crushing, with $45^{\circ}$ sample as a turning point. Li et al. [43] analyzed the influence of bamboo lamination thickness, end distance and bolt diameter on the dowel-bearing strength. The results showed that the thickness of lamination had little effect on strength; when the end distance was not less than $64 \mathrm{~mm}$, the influence of end distance was not significant; with the increase of bolt diameter, the dowel bearing strength approximately linear decreased.

Zhou et al. [44] carried out monotonic loading tests on 15 PBSL specimens in parallel to the grain direction and 15 PBSL specimens in perpendicular to the grain direction. The results showed that the distribution of ultimate strength along grain direction was relatively stable, with an average value of 91.59 $\mathrm{MPa}$, and the failure of specimens showed obvious brittle characteristics; while the strength in perpendicular to the grain direction of the specimens varied greatly, of which the average value is 71.81 $\mathrm{MPa}$, while the failure showed good ductility. Zhou et al. [45] designed 5 groups of specimens with di $\square$ erence only in bolt diameter in order to study the influence of bolt diameter on the embedding strength of PBSL. It was found that the yield strength was stable, and the coefficient of variation was between 5.88\% to $13.34 \%$; with the increase of bolt diameter, the yielding strength decreased.

Cui et al. [46] studied the influence of temperature on the embedding strength of PBSL. The results showed that the average ultimate strength was $75.2 \mathrm{MPa}$ at $20^{\circ} \mathrm{C}$. The bearing strength gradually decreased with the increase of temperature between $20^{\circ} \mathrm{C}$ to $110^{\circ} \mathrm{C}$. While in the temperature range from $110^{\circ} \mathrm{C}$ to $170{ }^{\circ} \mathrm{C}$, the strength increased because of the water evaporation. When the temperature continued to rise between $170{ }^{\circ} \mathrm{C}$ and $270{ }^{\circ} \mathrm{C}$, the strength decreased again due to the decomposition of bamboo fibers at high temperature. When the temperature arrived at $270{ }^{\circ} \mathrm{C}$, the embedding strength was only 9.6 MPa. Tang [47] found that the embedding strength parallel to grain of PBSL was directly affected by the compressive strength parallel to grain, while the embedding strength perpendicular to grain was affected by shear strength perpendicular to grain and bonding strength between layers.

Khoshbakht et al. [48] prepared specimens according to ASTM standard. The dowel-bearing strength of LBL was studied by experiment and finite element analysis. It was found that the failure area of the specimens occurred off-center of the contact region and was controlled by the shear stress-to-strength ratio. The tensile stress perpendicular to grain was often the primary cause of wood failure and was regarded as a secondary cause of failure. The friction coefficient was the critical factor to predict shear stress. Khoshbakht et al. [49] also evaluated the applicability of the testing method of dowel-bearing strength in ASTM D5764 standard for LBL. Three-dimensional bilinear finite element models for half-hole and fullhole were established. Based on Tsai-Wu failure criterion, the failure mechanism of half-hole and full-hole specimens was analyzed. The experimental and simulation results showed that the failure mechanism of half-hole and full-hole specimens was different and therefore care should be taken to select a reasonable test method suitable for engineered bamboo.

In summary, scholars have considered the influence of different factors on the embedding strength of engineered bamboo. The main factors are material specific gravity, bolt diameter, end distance, loading direction, moisture content, grain direction, external temperature et al. However, most of the existing studies aimed at parallel bamboo strand lumber, and a few aimed at other types of engineered bamboo. The universality of the existing conclusions needs more analysis and verification by a large number of 
experimental studies.

\subsection{Study on Performance of Bolted Joint}

Scholars have carried out experimental research on the bolted connection of engineered bamboo. Li [42] selected end distance, the thickness of main member and bolt diameter as the influencing factors to study the bearing capacity of single-bolted joint. It was found that the initial stiffness, yield stiffness, yield load, ultimate load and ductility of the joint were affected to different degrees by the three factors. The ultimate load decreased with increasing end distance or bolt diameter but increased with the thickness of the main member increasing. There were two main effective failure modes for single-bolted joints, which were "one hinge" and "two hinges" failure mode. Both modes could fully exploit the mechanical properties of the material. Based on Foschi model, the experimental data were fitted, and the thickness of the main member was recommended to be set to $90 \mathrm{~mm}$.

Li [42] also carried out experimental studies on multi-bolted joints, and analyzed the effect of the number of bolt rows, row space, space between the adjacent bolts and the number of bolts per row on the bearing capacity of the joints. The results showed that with the increase of space between adjacent bolts, the failure mode of the specimens gradually changed from the mixture of row split and 'one hinge' yield to 'one hinge' yield; with the number of bolt rows increased, the failure changed from single split to both sides split; with the increase of row space, the split failure of the specimen gradually disappeared, only the dowelbearing failure and hinge yield failure occurred; the load distribution of multi-bolt joints was not uniform, resulting in uneven deformation of bolts.

Zhang et al. [50] studied the bearing capacity and failure mode of the bolted joints. The experiment results showed that the main member and bolts were destroyed at the same time, which indicated that the joints had good overall mechanical properties and could ensure the effective transmission of shear force. Zhong et al. [51] conducted an experimental study on the compression performance of bolted joints with steel splint. The effects of board thickness and bolt diameter on stiffness, yield load and failure mode were analyzed. It was found that the failure modes of the joints were affected by both bolt diameter and thickness of bamboo board: with the increase of bolt diameter, the initial stiffness and yield load of the joints increased approximately linearly by $58.2 \%$ and $65.6 \%$ respectively (diameter of bolts were $12 \mathrm{~mm}$ and $16 \mathrm{~mm}$, thickness of board was $60 \mathrm{~mm}$ ); with the increase of the thickness of the board, the ultimate load and ductility coefficient could be significantly increased by $19.7 \%$ and $36.3 \%$ (diameter of bolts were $12 \mathrm{~mm}$, thickness of boards were $60 \mathrm{~mm}$ and $90 \mathrm{~mm}$ ).

Yang [52] analyzed the failure mode and bearing capacity of the GluBam bolted joints according to the tightening force of the bolt and the thickness of the main board. The results showed that the bolted joints had high strength and stiffness, and could ensure the reliable transmission of shear force; the joint with tightening force occurred buckling failure mode in the main member and the side member (Fig. 6); the thickness of the main member had little effect on the bearing capacity. Yang [53] also studied the tensile properties of GluBam bolt joints around factors such as edge distance and end distance. Two main failure modes, which were shear surface extraction and net section broken (Fig. 6), were obtained. It was found that GluBam single-bolted joints had high bearing capacity and good ductility along the main grain direction.
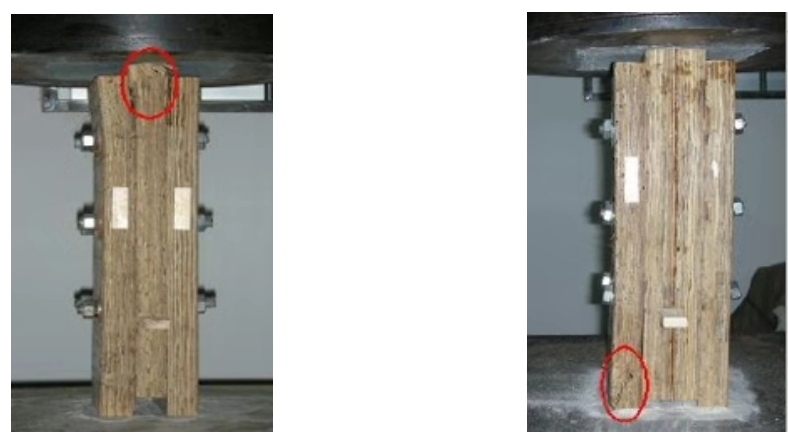


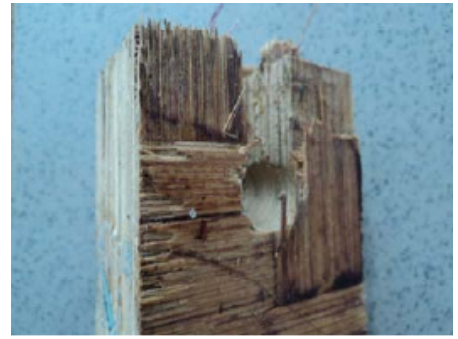

(c) Shear surface extraction

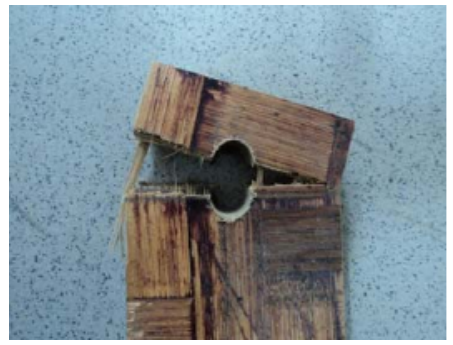

(d) Net section broken

Figure 6: Test specimen of Yang [52], [53]

Feng [54] studied the lateral load-carrying capacity of bolted joints of four GluBam beam-column frame by monotonic and cyclic test (Fig. 7). The results showed that the bolts were not uniformly loaded: under monotonic loading, the bolts in the middle part could hardly bear the load, while under cyclic loading, the middle bolt could also participate in the seismic energy dissipation. Through the analysis of joint rotation, it was found that the joint was semi-rigid; the tearing of GluBam material was the main reason of joint failure. Zhou et al. [55] studied the mechanical properties, failure modes and failure mechanisms of the bolted PBSL-steel-PBSL joints by tensile test, and considered the thickness of side member and the end distance of bolts as impact factors. It was found that with the increase of the thickness of side member, the failure modes of joints changed from pure groove crushing to a mixed mode of groove crushing and bolt bending, and the bearing capacity and ductility of joints increased as well; the bearing capacity increased with the increase of end distance, while the effect could be neglected when the end distance was greater than $7 \mathrm{~d}$ ( $\mathrm{d}$ is the diameter of bolt).

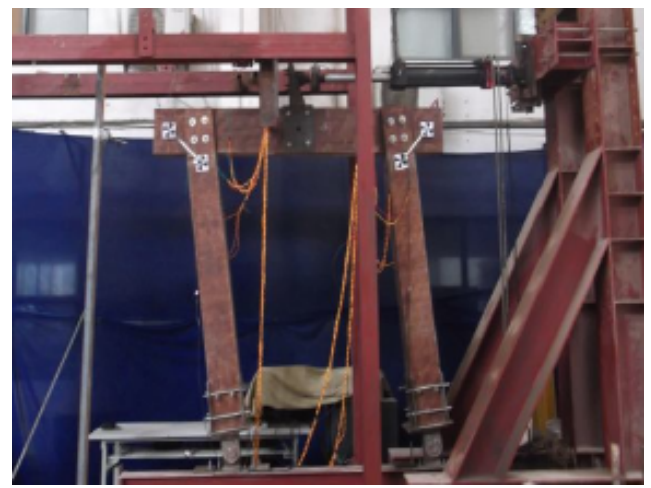

(a) Loading of GluBam frame

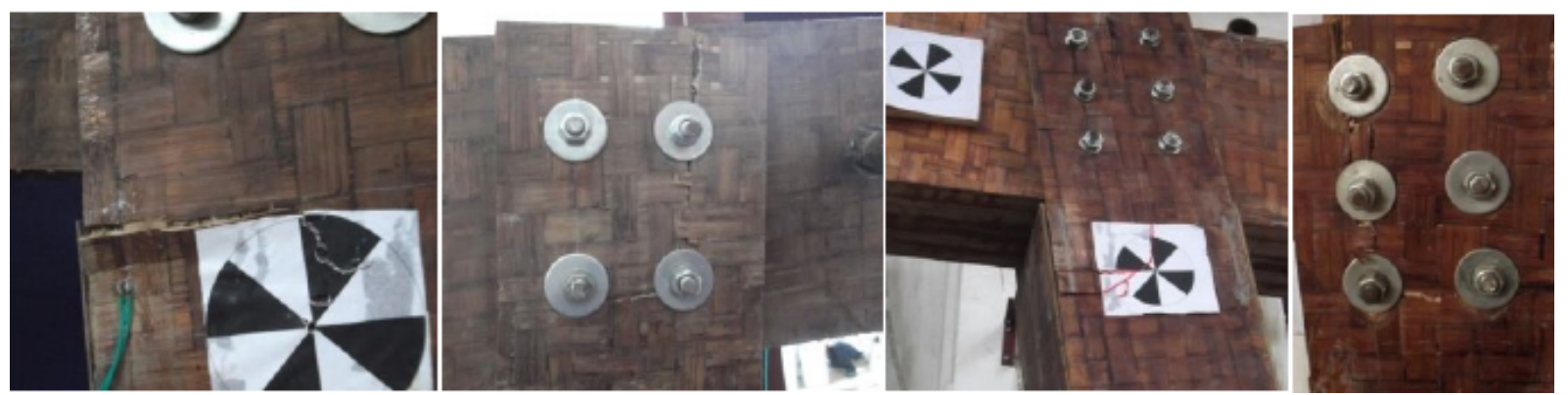

(b) Failure of test specimens 
Figure 7: Test specimen of Feng [55]

Debije [56] studied the mechanical properties of LBL-steel-LBL bolted joints through a large number of experiments, and observed a variety of failure modes. Dai [57] studied the mechanical properties of single-bolted joints in parallel and perpendicular to the grain direction of PBSL with end distance and edge distance as the impact factors. The results showed that the failure modes of single-bolted joints could be divided into two types. The first was the failure controlled by end distance or edge distance. Within a certain range, the ultimate load of materials increased with the increase of end distance or edge distance. The second was the failure controlled by the strength of the material. The holes on the specimens were enlarged when damaged.

Wang [58] carried out 12 groups of single-bolted joints with steel splints under uniaxial tension at room temperature firstly. The effects of bamboo thickness, bolt diameter, end distance and the number of bolts on the bearing capacity of the joints were studied. The test results showed that each variable had different degrees of influence on the bearing capacity and failure mode of the joints. Based on the scenario of heating standard, the fire resistance of 24 groups at high temperature was tested. The results showed that the fire resistance limit time of the specimens increased by $54 \%$ on average when the load level decreased from 0.3 to 0.1 ( 0.3 to 0.1 times the ultimate bearing capacity), and the average fire resistance limit time increased significantly with the increase of the end distance and the edge distance.

Reynolds et al. [59] compared the mechanical properties of the bolted joints of LBL and spruce, and found that the failure modes of the two joints were significantly different (Fig. 8). The LBL failed most often by the formation of a shear plug, and the failure occurred at the location of maximum shear stress. The spruce failed by a single split, which occurred at the location of maximum tensile stress perpendicular to the grain. Therefore, the design method for timber structure may not be directly applied to the design of LBL. Qin [60] studied the corner joint performance of LBL furniture. The results showed that the average tensile strength of bolt connection was $1354.3 \mathrm{~N}$ and the average compressive strength was $652.9 \mathrm{~N}$, which indicated that the corner was more easily damaged under pressure than under tension.
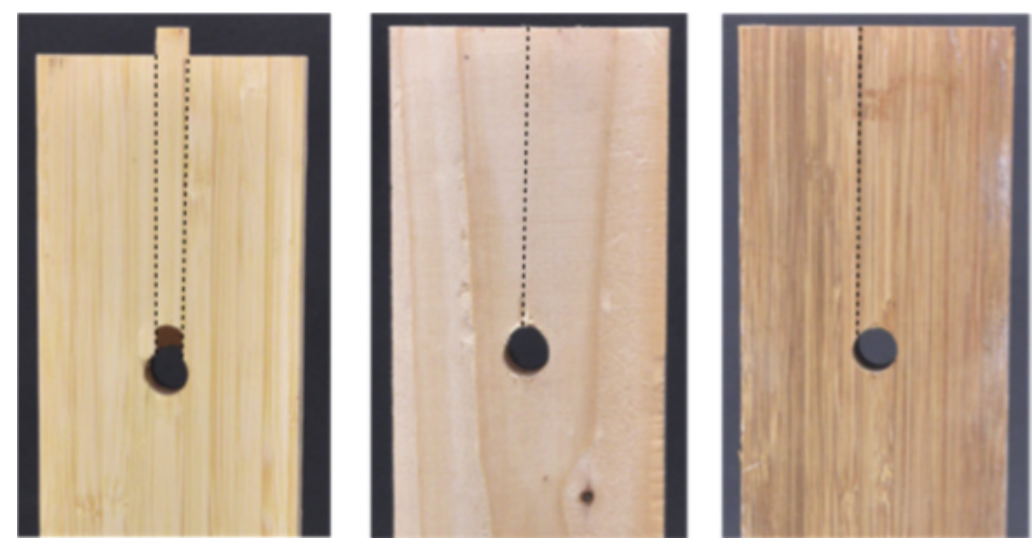

(a) A shear plug in bleached bamboo (b) A crack in spruce (c) A crack in caramelized bamboo

Figure 8: Test specimen of Reynolds [59]

Zhou et al. [61] proposed an energy dissipation joint of bamboo/timber structure (Fig. 9). The mechanical properties of the joint under cyclic loading were studied. The results showed that the thickness of the hollow steel column had a significant effect on the energy dissipation capacity and strength. The failure of the joint was caused by the buckling in the compression. Huang et al. [62] proposed a joint form for connecting engineered bamboo beams and steel columns (Fig. 10). The joint is composed of a steel hinge, steel brackets and energy dissipation panel (EDP). The seismic performance of the frame was studied by lateral cyclic loading test. The results showed that the hysteresis loops of the frame showed less pinching than that of frames with dowel- or bolt-type connections; after the yielding of EDP, the joint could provide more than $10 \%$ damping for the frame. 


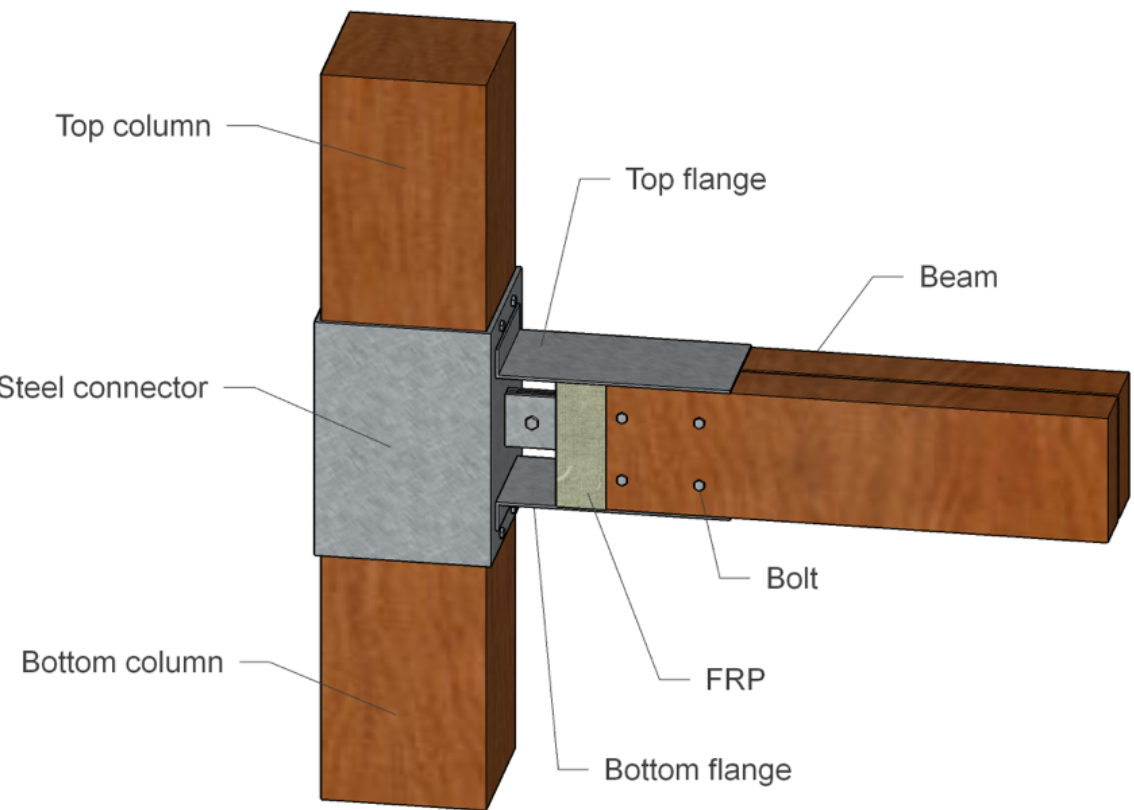

Figure 9: Zhou jointing method [61]

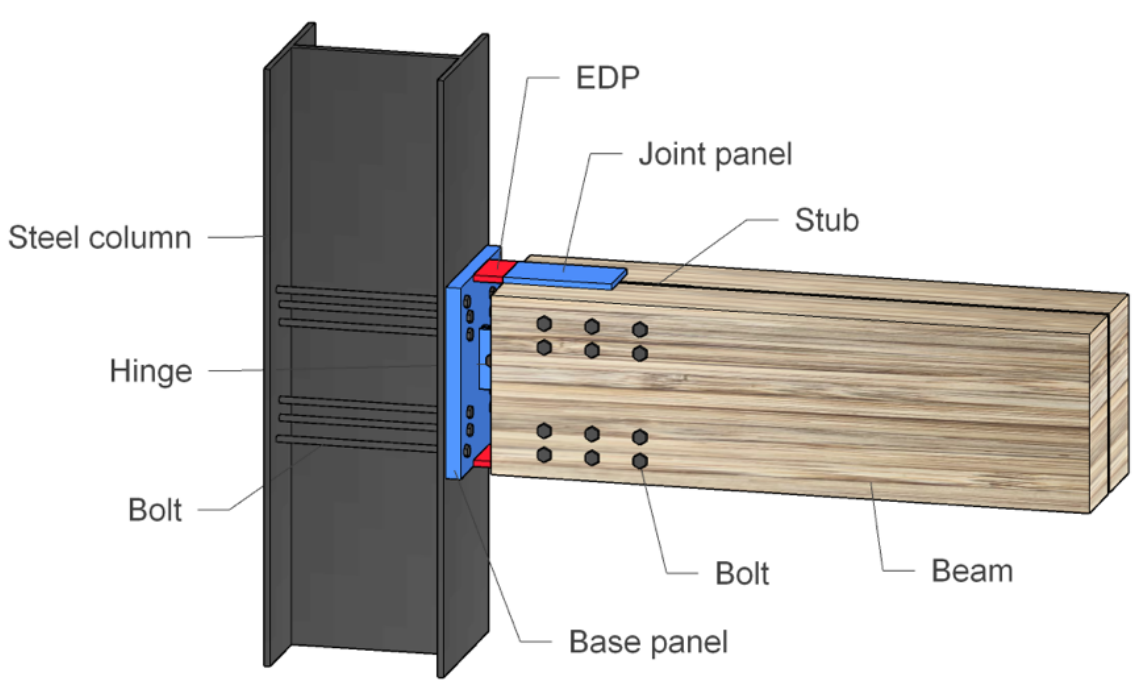

Figure 10: Huang jointing method [62]

Tang et al. [63] conducted a study on the LBL single-bolted joints and multiple-bolted joints. The influence of the thickness of laminated bamboo strips, end distance, bolt diameter and configuration of the bolts on the bearing capacity was considered. It was found that there were three typical failure modes, which were the longitudinal splitting, shear out, and combined longitudinal splitting and bamboo crushing. The results for multiple-bolted joint showed that stagger configuration of the bolts improved the capacity of the multiple-bolted joints. Zhang et al. [64] found that although the overall load carrying capacity of MPB (Mould-pressed Bamboo) glued bamboo (Fig. 11) was relatively low, the bolted joints had good performance and high strength. The failure yield load reached $7.624 \mathrm{kN}$ on average. 

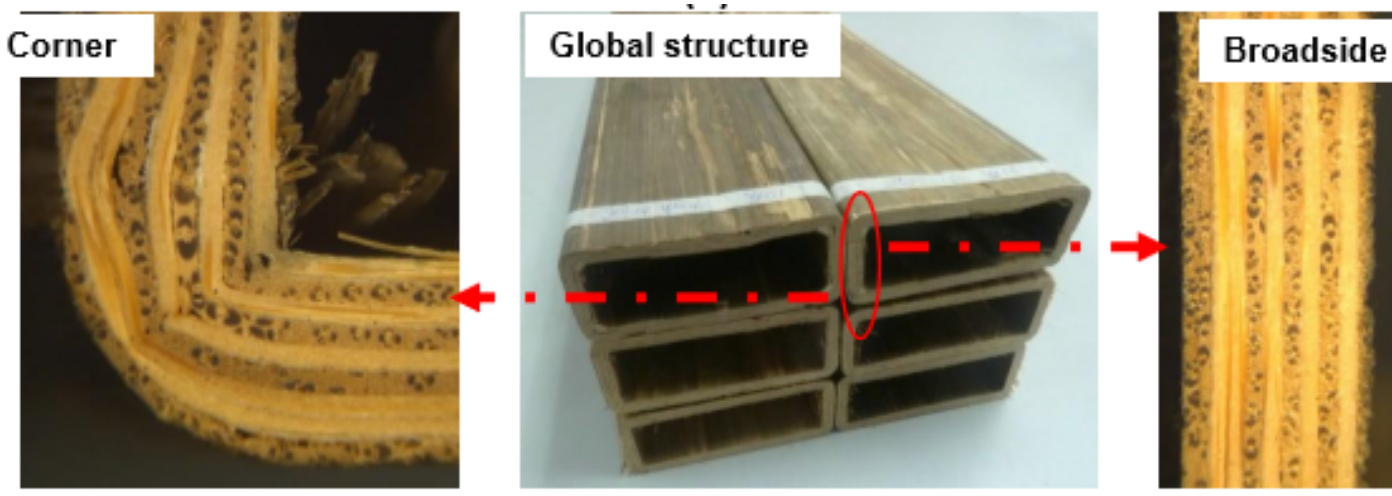

Figure 11: MPB glued bamboo [64]

It can be seen that the mechanical properties of bolted connections are very complex, which are affected by many factors such as the characteristics of the connecting material, bolt diameter, bolt end distance and edge distance. In the design of timber structure, the bearing strength of bolted joints is obtained through a large number of experiments and theoretical analysis. Although scholars have carried out some experimental studies on bolted joints of engineered bamboo structures, the number of tests is far from enough.

\subsection{Study on calculation method of engineered bamboo bolted joints}

Gatóo et al. [65] described the existing design and testing standards for full culm bamboo from various countries, and analyzed the relations between production, application, economic benefits and standardization. It can be seen that codes and standards are important for specific implement. However, there is no unified design theory and calculation system for engineered bamboo structures yet, which becomes a major barrier to promote the utilization of new materials in construction area. The investigation on timber structures started much earlier, and the researchers have considered many impact factors. Until now, there are still many comprehensive experiments and theoretical basis appearing [66], [67], [68], [69], [70]. The structural form of engineered bamboo structures is analogous to that of timber structures. Thus, most of the existing literature evaluates the applicability of national codes and standards of timber structures in bamboo structures, and makes corresponding adjustments and improvements on this basis.

Based on the experimental data, Eratodi et al. [39] obtained the relations between the specific gravity $\mathrm{G}$ of glue-laminated bamboo and the embedding strength. The embedding strength could be well predicted using $78.4 \mathrm{G}$ for parallel to grain radial, $72.79 \mathrm{G}$ for parallel to grain tangential, and $69.96 \mathrm{G}$ for perpendicular to grain radial. Ramirez et al. [40] found that the local behavior of the zone under the fastener was different from the bulk material, and proposed expressions to determine local properties as functions of the bulk properties. Equations for the bearing strength in terms of the specimen width-to-fastener diameter ratio were also proposed. Li [42] found through experiments that the predicted values of embedding strength of PBSL in Eurocode 5 and NDS-1997 were relatively small, and established the calculation formula for different texture direction, with bolt diameter, moisture content, and texture angle as independent variables. Li [42] compared the calculation results of NDS-1997, CSA, Eurocode 5, 'GB 50005-2003 Code for design of timber structures', and 'GB/T 50329-2002 Standard for test methods of timber structures', and proposed the calculation formula suitable for single-bolted and multi-bolted connections for PBSL.

Li [43] obtained influence coefficient of bolt diameter by regression analysis and established a simplified theoretical calculation formula of dowel bearing strength, of which the results had a good agreement with test results. Zhou et al. [45] proved that the theoretical equation on embedding yielding strength of wood in NDS-2015 and Eurocode 5 could be applied to PBSL. Cui et al. [46] suggested that Eurocode 5 could be used to calculate the embedding strength of PBSL in normal temperature by comparing 
with Eurocode 5, CSA, 'Manual for design of timber structures (Chinese)', 'GB/T 50708-2012 Technical code of glued laminated timber structures', and NDS-1997, and put forward a fitting formula for the reduction coefficient of embedding strength in high temperature. Zhang et al. [50] found that the design bearing capacity of bolted connection could be relatively accurately obtained by $5 \%$ bolt diameter offset (Fig. 12), and proposed a reduction coefficient of 0.95 according to the 'GB/T 50329-2002 Standard for test methods of timber structures'.

Yang [52] compared the calculation results of NDS-2005, 'GB 50005-2003 Code for design of timber structures', and 'GB/T 50329-2002 Standard for test methods of timber structures', and found that the calculation values from NDS-2005 were not desirable, while the calculation values of Chinese codes were too conservative, and the bearing capacity obtained by $5 \%$ bolt diameter offset could be used as the design standard. According to the two failure modes, Yang [53] obtained the nominal theoretical formula for calculating the tensile strength of GluBam single bolt, revised it by regression, and established the formula for calculating the maximum load, but the results were still very discrete.

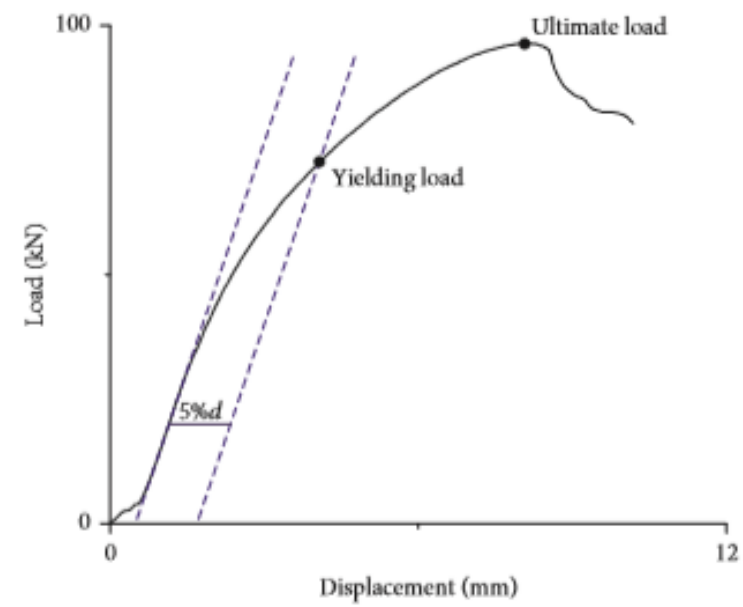

Figure 12: 5\% bolt diameter offset method to evaluate the yielding load [45]

Zhou et al. [55] compared the test results with the calculation results of the codes, and found that the formula recommended in the 'Manual for design of timber structures (Chinese)' was suitable, while the calculation results obtained by 'GB 50005-2003 Code for design of timber structures' and NDS-2012 were conservative and the calculation error could be more than $200 \%$. On the basis of EYM and in combination with the failure form of specimens, Dai [57] established a mechanical model for predicting the bearing capacity of single-bolted joints along the grain direction of PBSL. Wang [58] found that Johansen's formula was applicable to calculate the bearing capacity of PBSL-steel-PBSL bolted joints under room temperature, and established the formula suitable for joints under high temperature. The calculation results showed that the theoretical calculation values had high accuracy when the temperature was determined.

Table 1 Calculation formula and methods

\begin{tabular}{c|c|c}
\hline Literature & Formula/Standard/Method & \multicolumn{1}{c}{ Note } \\
\hline Eratodi et al. [39] & $\mathrm{F}_{e}=78.4 G$ (parallel to grain radial) & $\mathrm{F}_{e}$ is the embedding strength; $G$ is \\
& $\mathrm{F}_{e}=72.79 G$ (parallel to grain tangential) & $\begin{array}{l}\text { the specific gravity of the glulam } \\
\text { bamboo. }\end{array}$ \\
\hline
\end{tabular}




\begin{tabular}{|c|c|c|}
\hline Ramirez et al. [40] & $\begin{array}{l}B S N_{\|}=-5.8 D+63.9 \\
B S N_{\perp}=-4.1 D+55.9 \\
B S B_{\|}=-0.44 D+67.5 \\
B S B_{\perp}=-0.55 D+36.9\end{array}$ & $\begin{array}{l}B S \text { is the embedding strength; } N \\
\text { is nail; } B \text { is the bar; } \| \text { means } \\
\text { parallel to the grain; } \perp \text { means } \\
\text { perpendicular to the grain; } D \text { is the } \\
\text { diameter; } R \text { is the width-to- } \\
\text { fastener diameter raito. }\end{array}$ \\
\hline $\mathrm{Li}[42]$ & $\begin{array}{c}f_{e, / /}=\left[-0.554\left(\frac{D}{10}\right)+1.853\right] f_{c, 0} \\
f_{e, \perp}=\left[3.673\left(\frac{D}{10}\right)^{2}-10.59\left(\frac{D}{10}\right)+10.15\right] f_{c, 90} \\
\left\{\begin{array}{l}f_{e}=91.144-1.217 m m \leq 22.2 \% \\
f_{e}=64.5 m>22.2 \%\end{array}\right. \\
\left\{\begin{array}{l}f_{e}=\frac{f_{e / /} f_{e 45^{\circ}}}{f_{e / /} \sin ^{2} \alpha+f_{e 45^{\circ}} \cos ^{2} \alpha} 0^{\circ} \leq \alpha \leq 45^{\circ} \\
f_{e}=\frac{f_{e 45_{e \perp}} f_{e}}{f_{e 45^{2}} \sin ^{2} \alpha+f_{e \perp} \cos ^{2} \alpha} 45^{\circ}<\alpha \leq 90^{\circ}\end{array}\right.\end{array}$ & $\begin{array}{l}f_{e / /} \text { is the embedding strength in } \\
\text { parallel to the grain direction; } f_{c, 0} \text { is } \\
\text { the compressive strength in parallel } \\
\text { to the grain direction; } f_{e, \perp} \text { is the } \\
\text { embedding strength in perpendicular } \\
\text { to the grain direction; } f_{c, 90} \text { is the } \\
\text { compressive strength in } \\
\text { perpendicular to the grain direction; } \\
D \text { is the diameter of bolt; } f_{e} \text { is the } \\
\text { embedding strength; } m \text { is the } \\
\text { moisture content; } f_{e 45} \text { is the } \\
\text { embedding strength in the } 45^{\circ} \\
\text { direction; } \alpha \text { is the angle. }\end{array}$ \\
\hline $\operatorname{Li}[42]$ & $P_{v}=\left(-0.0009\left(\frac{c}{d}\right)^{2}+0.0145\left(\frac{c}{d}\right)-0.0173\right) n_{r} n^{0.94} d^{\frac{3}{2}} \sqrt{\frac{a_{1} f_{e}}{13}}$ & $\begin{array}{l}N_{v} \text { is the bearing capacity in each } \\
\text { shear plane of single-bolted joints; } \\
c \text { is the thickness of main member; } \\
d \text { is the diameter of bolt; } f_{e} \text { is the } \\
\text { embedding strength; } P_{v} \text { is the } \\
\text { bearing capacity in each shear plane } \\
\text { of multi-bolted joints; } n_{r} \text { is the } \\
\text { number of bolt rows; } n \text { is the } \\
\text { number of bolts per row; } a_{1} \text { is the } \\
\text { space between the adjacent bolts } \\
\text { along grain direction. }\end{array}$ \\
\hline $\mathrm{Li}[43]$ & $\begin{array}{c}f_{\mathrm{e}}=0.88 K_{D} f_{\mathrm{c}, 0} \\
K_{D}=1.797-0.792\left(\frac{D}{12}\right)\end{array}$ & $\begin{array}{l}f_{e} \text { is the embedding strength; } f_{c, 0} \\
\text { is the compressive strength in } \\
\text { parallel to the grain direction; } K_{D} \text { is } \\
\text { the influence coefficient; } D \text { is the } \\
\text { diameter of bolt. }\end{array}$ \\
\hline Zhou et al. [45] & NDS-2015 and Eurocode 5 & \\
\hline & $\begin{array}{l}\text { Eurocode } 5 \\
\text { 1. } 12-0.0059 T, 20 \mathrm{C}, T<110^{\circ} \mathrm{C}\end{array}$ & $\begin{array}{l}\eta_{T} \text { is reduction coefficient; } T \text { is } \\
\text { the temperature; }\end{array}$ \\
\hline
\end{tabular}




$$
p=n \times p_{\text {single }} \times C_{g}
$$

$p$ is strength of connection; $n$ is the number of bolt; $p_{\text {single }}$ is strength of single bolt connection; $C_{g}$ is the reduction factor.

It can be seen that scholars have done some research on the calculation method of engineered bamboo bolted joints, but most of the existing studies just follow the codes and standards for timber structure. For the design of engineered bamboo bolted joints, there is no unified design theory and calculation system yet. Although both wood and engineered bamboo are bio-materials, there are some differences in their structure and mechanical properties. Thus, the specifications that conform to the characteristics of engineered bamboo materials should be developed as soon as possible.

\section{Carpentry Joints}

\subsection{Tenon-mortise joint}

Tenons and mortises made by carpenters realize the connections of components in Chinese ancient timber architectures. It is characterized by the fact that no metal parts are used in the objects, which reflects the ancient Chinese culture and wisdom. Tenon-mortise joint is a kind of connection method that tenon is pressed into the mortise. The convex part is called tenon, and the concave part is called mortise. It has strong semi-rigid characteristics and has the ability to resist tension, compression, bending and torsion. However, under the long-term load, tenons may be pulled out or broken, and mortise may be damaged [71]. There are many kinds of tenons, among which rectangular tenon, round tenon, and oval tenon are the common forms. Because of the relatively simple and fast processing technology, they are widely used in solid wood furniture manufacturing enterprises.

Scholars have carried out experimental research and analysis on the performance of tenon-mortise joint in bamboo structure. In order to study the pull-out resistance of tenon-mortise joints of LBL, Li [72] comprehensively considered the influence of gluing method, tenon shape, joint area, the diameter of round tenon, insertion depth, and magnitude of interference. It was found that the pull-out resistance reached the maximum when both tenon and mortise were coated with glue; the larger the joint area between tenon and mortise, the larger the pull-out resistance and the bending strength; the pull-out resistance of rectangular tenon joint is larger than that of round tenon joint; the influence of the diameter of round tenon, insertion depth and magnitude of interference on the joint strength decreased in turn.

$\mathrm{Xu}$ [73] studied the influence of tolerance parameter $\alpha$ and $\beta$ of LBL oval tenon on pull-out resistance 
( $\alpha$ and $\beta$ are the difference between the width of mortise and tenon, the difference between the thickness of mortise and tenon respectively), and obtained the relations between the two parameters and the ultimate pull-out resistance through fitting the experimental data. Huang [74] found that in a certain range, the tensile strength of oval tenon increased with the increase of $\alpha$ and $\beta$, but decreased when $\alpha$ was greater than 0.4 $\mathrm{mm}$ or $\beta$ was greater than $0.1 \mathrm{~mm}$; polyurethane adhesive was superior to white emulsion in enhancing the pull-out strength of tenon, which illustrated that selection of adhesive with strong bonding ability could effectively improve the pull-out strength of tenon; the bending strength of oval tenon made by PBSL was far higher than that of oval tenon made by common solid wood.

It can be seen that although some scholars have carried out some research on tenon-mortise joints made by engineered bamboo, and considered many influencing factors, but the current tenon-mortise joints mainly aimed at bamboo furniture. There is a lack of research on the tenon-mortise joint for utility in bamboo building structures.

\subsection{Nail/Screw Joint and Truss Plate Joint}

There are a few studies on nail connection and truss plate connection of engineered bamboo in the existing literature. The nail connection has dispersed force transmission, and its performance cannot meet the needs of the connection of larger components. Huang [74] studied the screw joints of PBSL furniture and analyzed the influence of screw type, hole diameter, and screw-in depth on the joint strength. The results showed that the screw-in depth and hole diameter had a significant influence on the pull-out resistance, while screw type had no apparent effect. Through the experiment, Li et al. [75] concluded similarly to Huang. It was found that with the decreasing of diameter of guiding hole and the increasing of screw-in depth, the joint strength was obviously increased. Li et al. [75] obtained the relation curves between screw type, hole diameter, screw-in depth and pull-out resistance respectively, and suggested that the suitable diameter of guiding hole was $80 \% \sim 90 \%$ of the diameter of the screw.

Zhang [76] optimized the thread parameters of the special screw (Fig. 13) for LBL by orthogonal test. The effects of the diameter of the hole, the depth and direction of screw insertion, and the number of disassembling and assembling of screw joints on the mechanical properties were discussed. The results showed that the joint strength decreased with the increase of the times of assembly and disassembly, and the two had a negative linear correlation. Chen et al. [77] found that the screw diameter, screw type and loading rate had no obvious influence on withdrawal resistance. However, the diameter of hole had significant influence, and suggested that the size of pilot hole should be $60 \sim 85 \%$ to the diameter of the screw. Sinha et al. [78] studied the lateral bearing capacity of edge connection and plate connection (Fig. 14) of LBL-OSB by static load test. The results showed that the bearing capacity of LBL-OSB nail joints is similar to that of conventional fir-OSB nail joints, and the bearing capacity of edge connection before yielding was higher than that of plate connection.

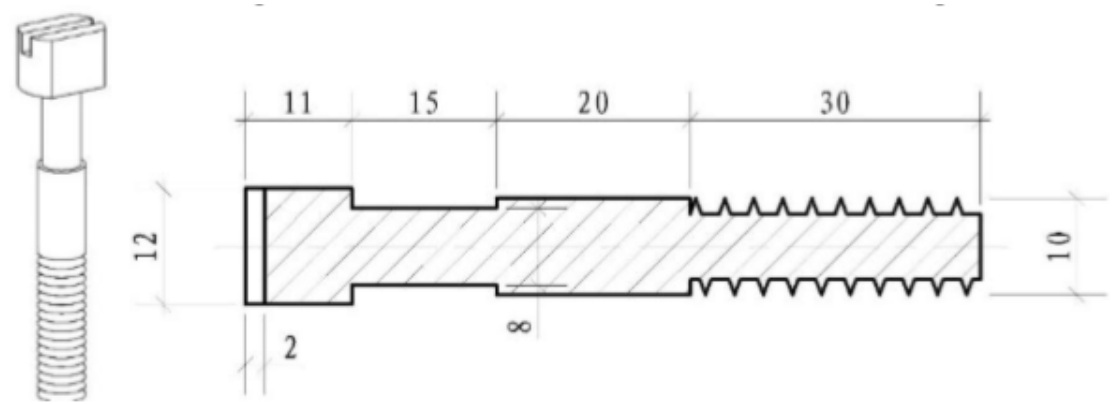

Figure 13: Schematic of special screw by Zhang [76] 


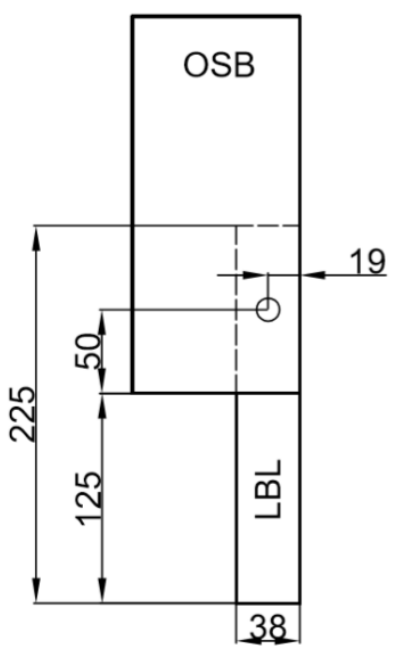

(a) edge connection

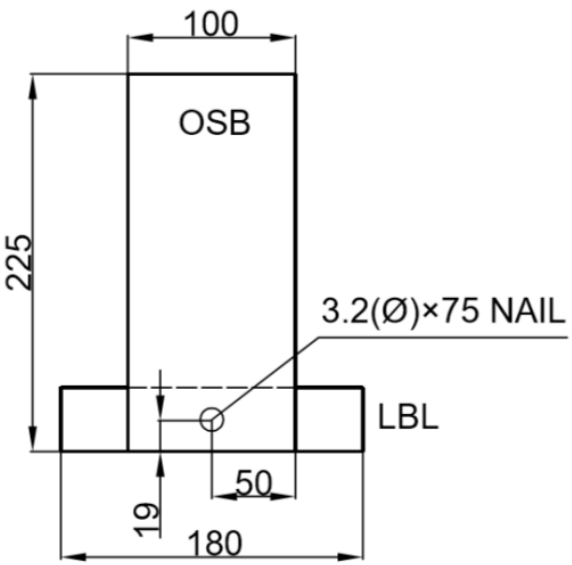

(b) plate connection

Figure 14: Schematic of connection geometries by Sinha [78]

Truss plate joints are made of galvanized steel sheet by one-way teeth beating. They are often used in light timber trusses with the characteristics of fast and convenient construction. However, the truss plate joint may also be the weak area of the whole truss, and its bearing capacity determines the bearing capacity of the whole truss. Wu [79] carried out tensile test on the joints with four connection conditions, of which the orientation between load and the main fiber direction of GluBam, load and main direction of truss plate was different (Fig. 15). Four failure modes, which were bamboo panel failure, tooth plate pull-out, tooth breakage and mixed mode of three, were observed. By comparing the ultimate strength of GluBam truss plate joints with timber truss plate joints, it was found that the joints had good ultimate strength. The tensile strength, shear strength and ultimate strength at special angles of the joints were also tested, which proved the applicability of the truss plate joints in engineered bamboo structures.

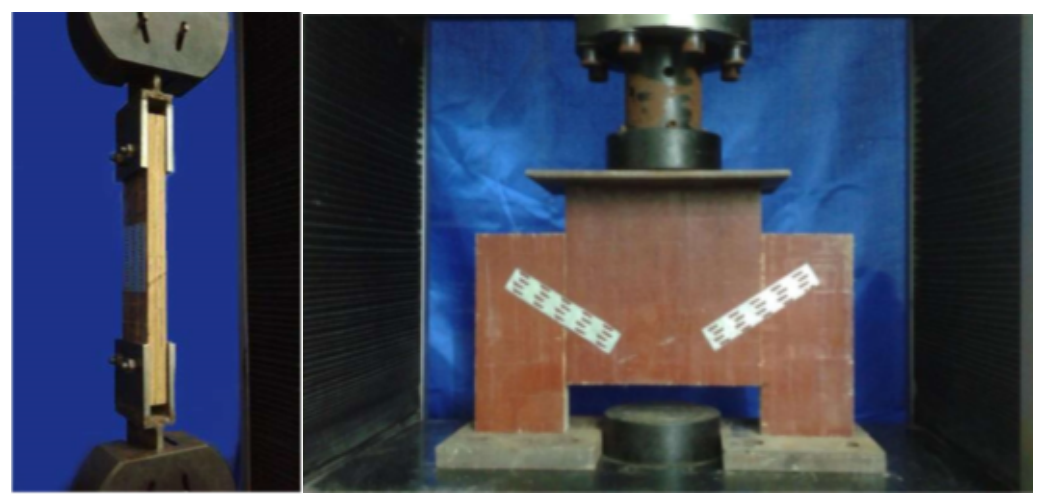

Figure 15: Truss plate joint test by $\mathrm{Wu}[79]$

Peng [17] studied the strength of GluBam truss plate joints at ten different angles through tensile tests. The results showed that the strength of joints was higher than that of the timber truss plate joints at most angles. Static loading tests were carried out on four GluBam trusses with $3 \mathrm{~m}$ span and $5.6 \mathrm{~m}$ span as well (Fig. 16). The ultimate bearing capacity, load-displacement curves and strain of some components were 
obtained. The results showed that the truss had a large strength reserve. The trusses were destroyed by the failure of the truss plate joints, which belonged to brittle failure.

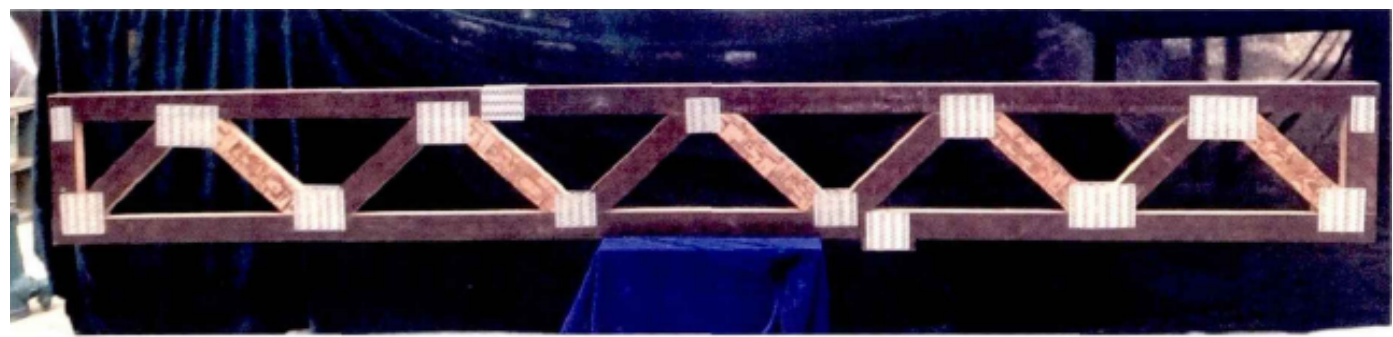

(a) GluBam trusses with $3 \mathrm{~m}$ span

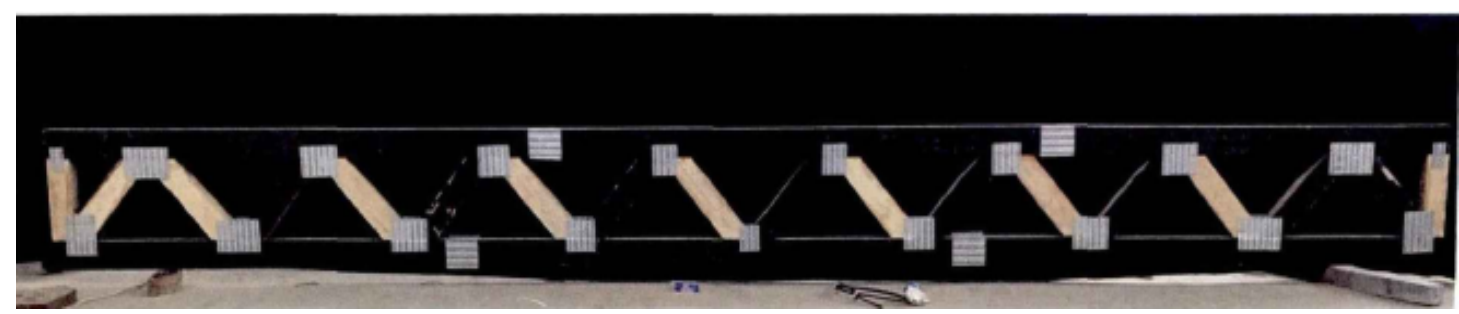

(b) GluBam trusses with $5 \mathrm{~m}$ span

Figure 16: Test specimen of Peng [17]

In summary, scholars have already conducted some research on the connection performance of engineered bamboo for different forms, and discussed the effect of various factors. However, compared with wood, the number of the experiment and theoretical depth are still insufficient. The mechanical properties of engineered bamboo joints have yet to be further studied.

\section{Engineering Example}
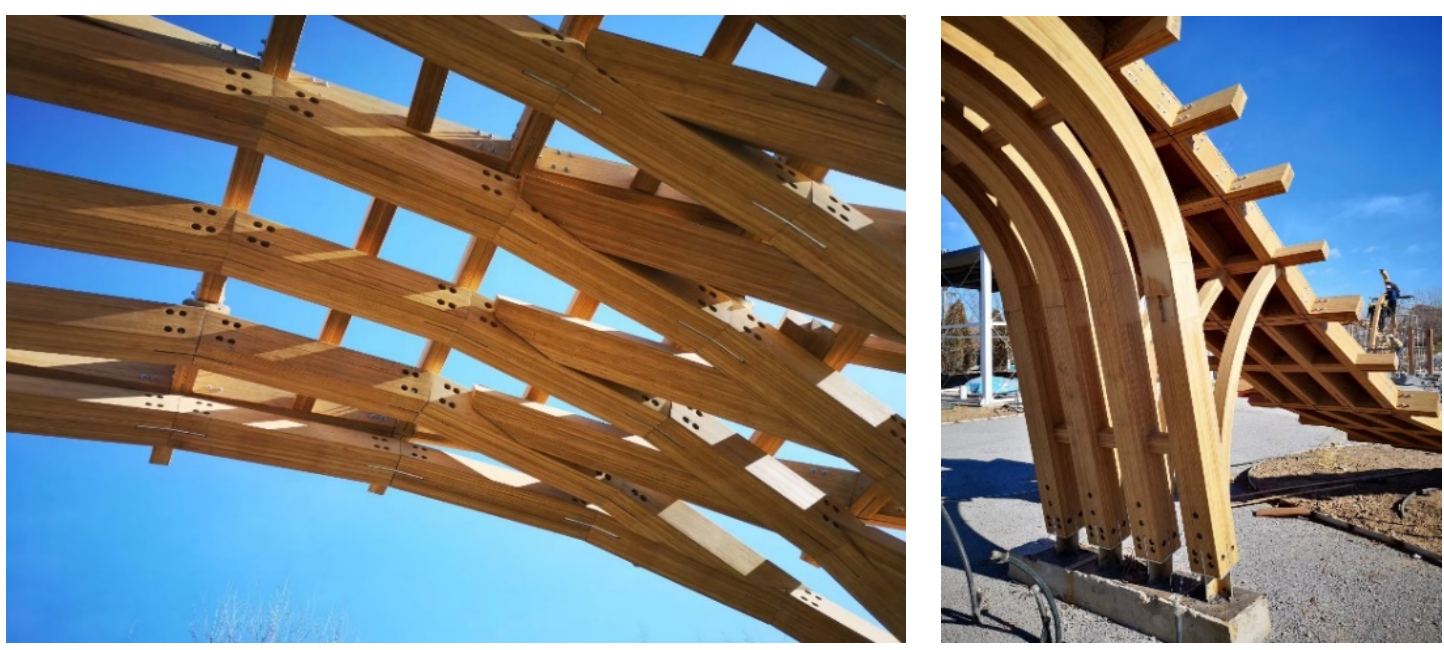

(a) Double-curved lattice structure

(b) Double-curved lattice structure 


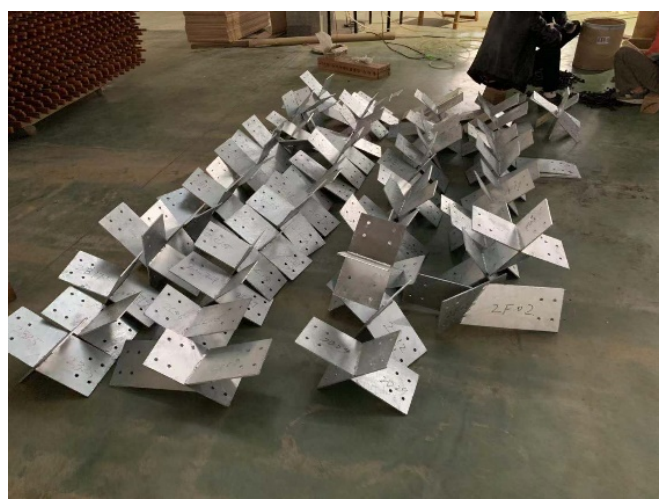

(c) Steel member joint with special configuration

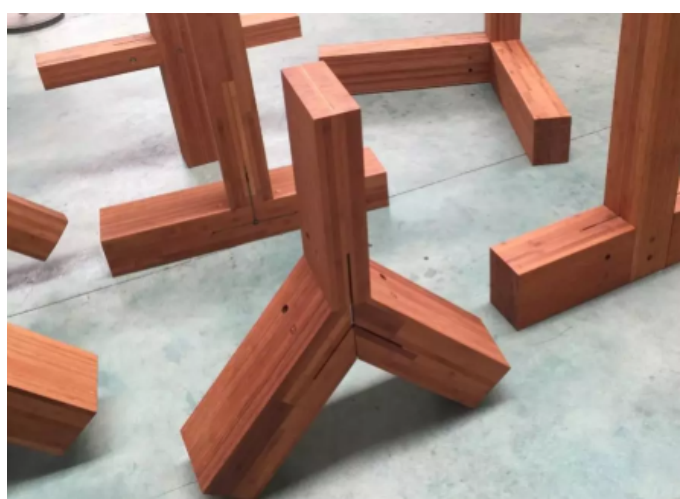

(d) LBL component with slot

Figure 17: LBL building with special geometry at 2019 the Beijing International Horticultural Exhibition (reproduced with permission of Zhenhua Xiong)

Figure 17 displays the construction process of LBL building with special-shaped, which was presented at 2019 the Beijing International Horticultural Exhibition. In order to meet the requirement of the spatial form, the double-curved lattice structure was adopted according to the mechanical properties of LBL. The internal and external arches adopt the multi-point connection at the top instead of the conventional vertical connection between the internal arch and purlin. The greatest advantage of this method is to avoid the tensile stress in the perpendicular to grain direction, but to transform it into the tensile stress along the grain direction through the special joint, so as to make better use of the material. The multi-point connection increases the reliability of the structure connection as well.

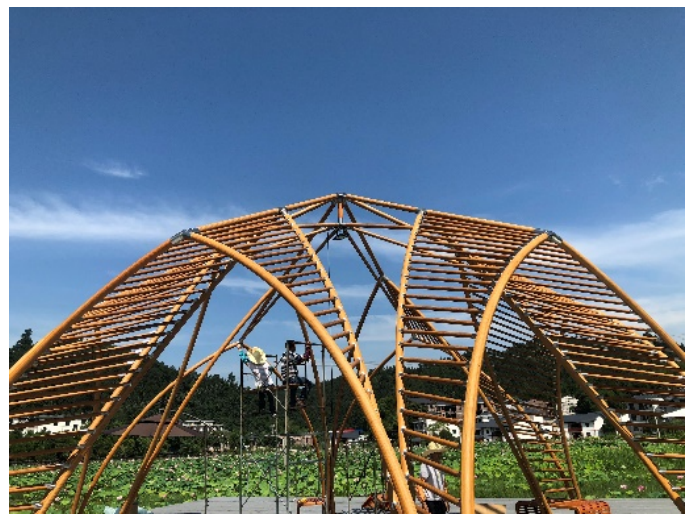

(a) Building skeleton

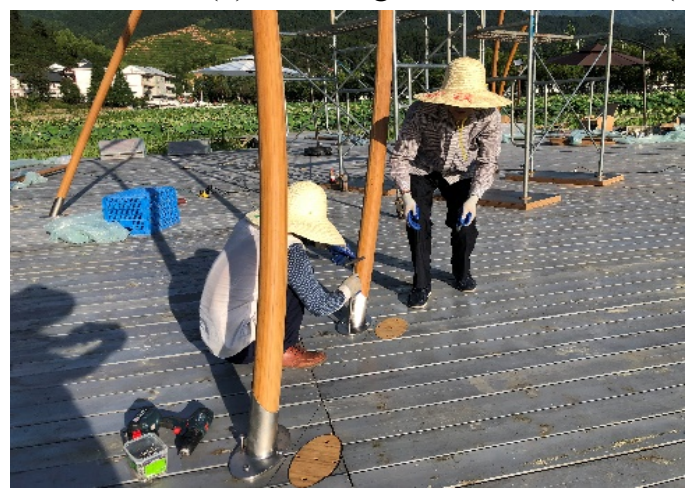

(c) Connection between curved column and floor

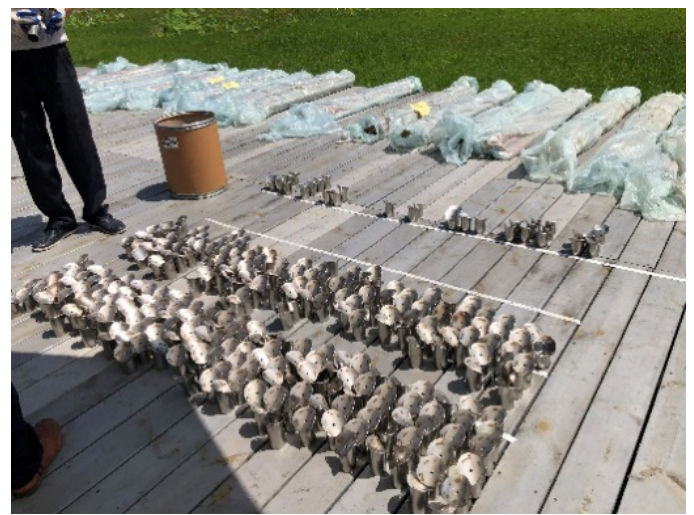

(b) Steel member joint with special configuration

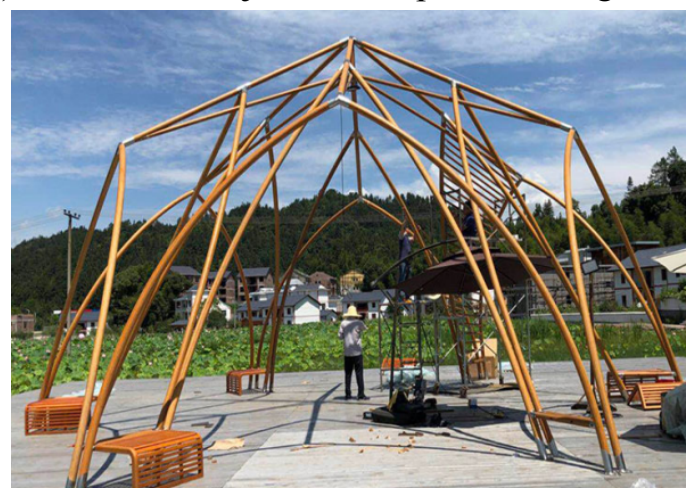

(d) Building skeleton 
Figure 18: LBL 'Lotus Pavilion' in Jinggangshan City (reproduced with permission of Zhenhua Xiong)

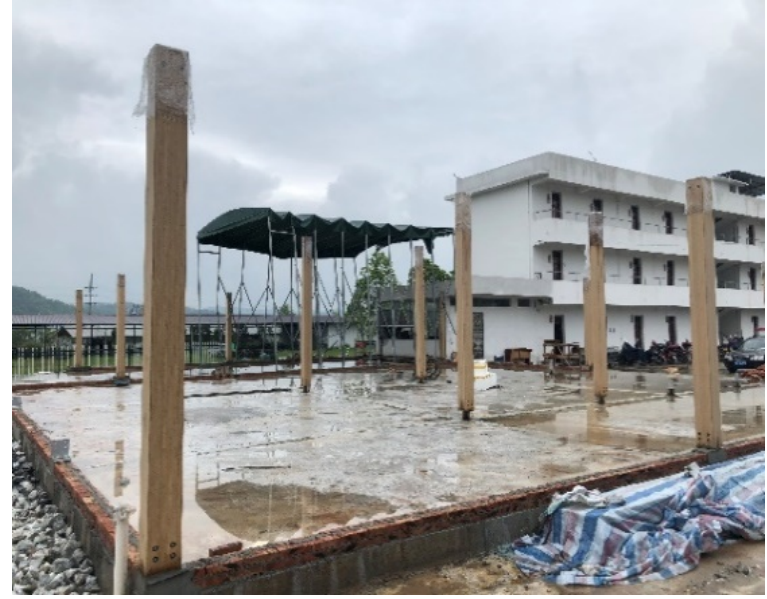

(a) Construction process

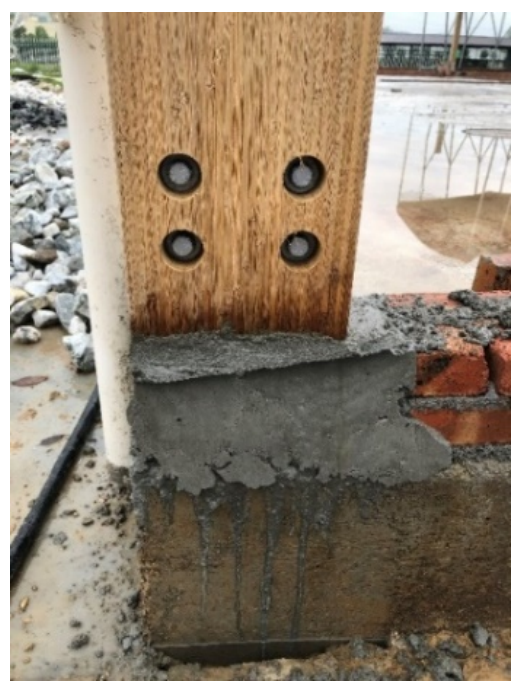

(c) Connection between LBL column and floor

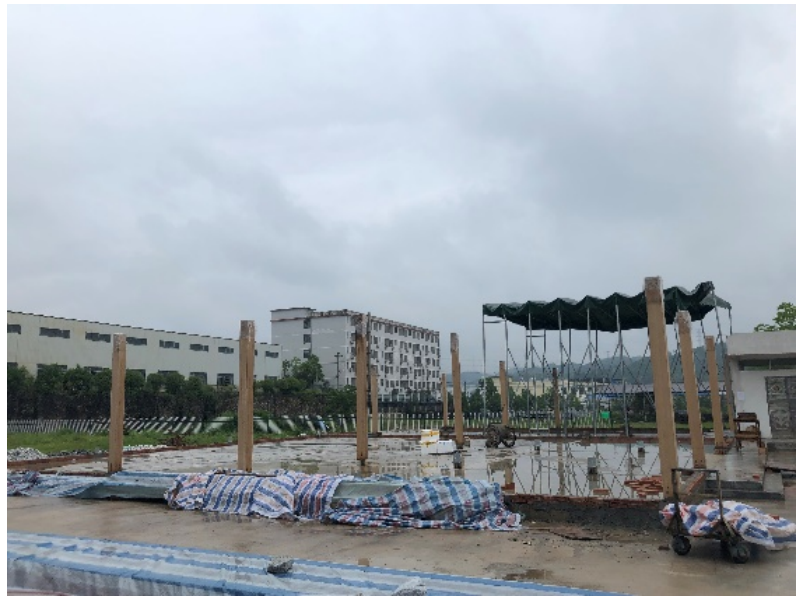

(b) Construction process

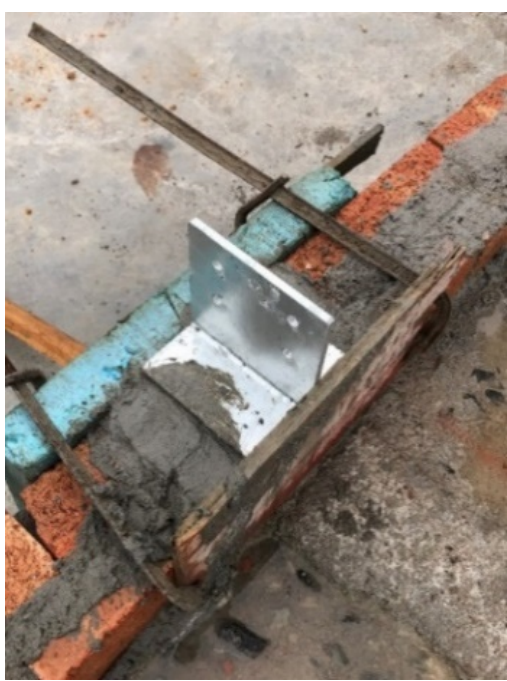

(d) Details of steel member joint

Figure 19: LBL office building in Ganzhou City (reproduced with permission of Chaokun Hong)

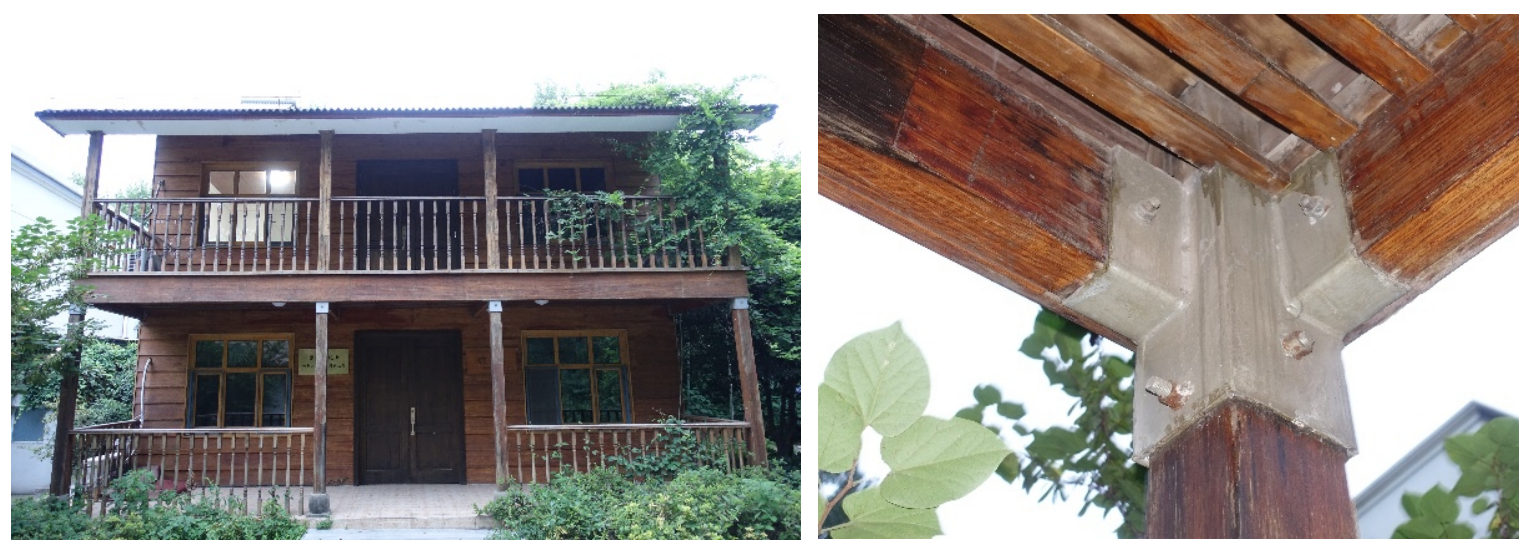

(a) Bamboo villa

(b) Connection between corner column and beam 

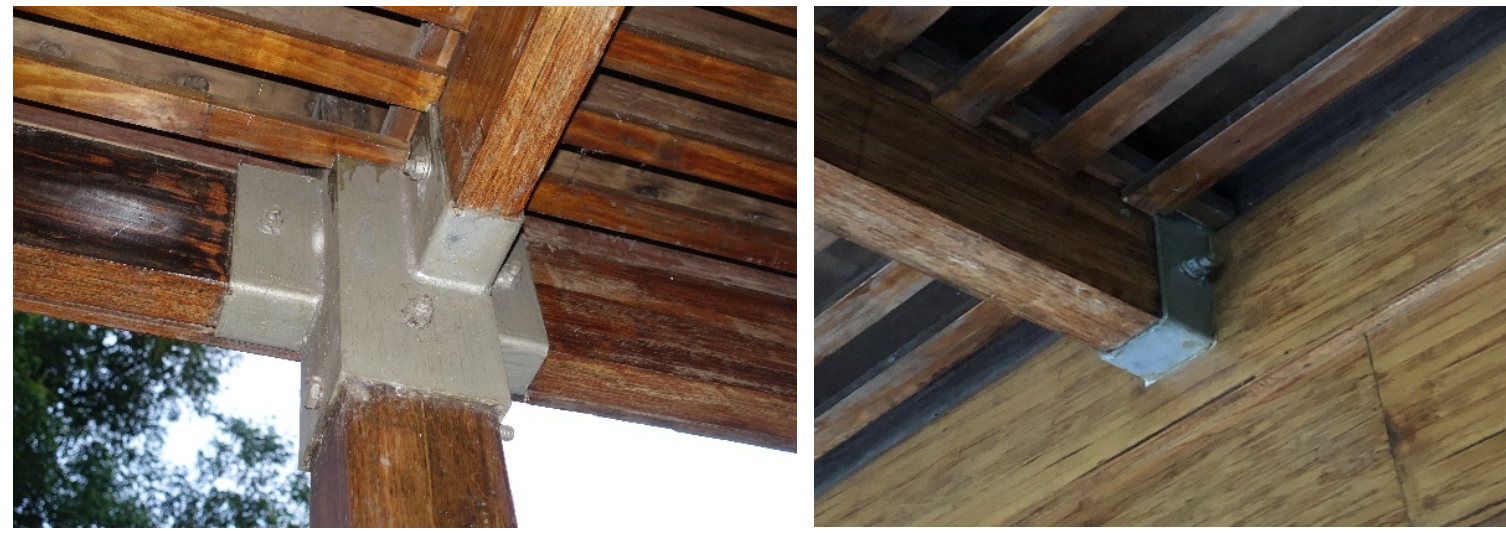

(c) Connection between middle column and beam (d) Connection between main beam and secondary beam

Figure 20: Earthquake-resistant bamboo villa in Nanjing Forestry University (Built in 2008, reproduced with permission of Chaokun Hong)

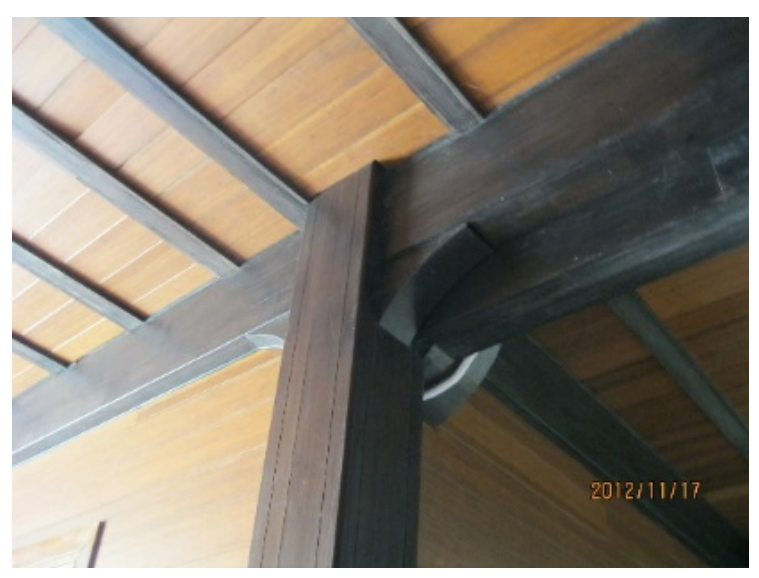

(a) Tenon-mortise joint

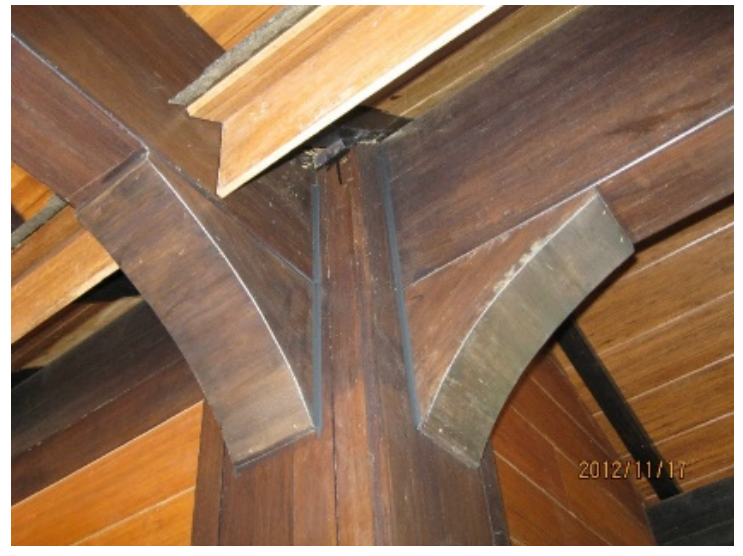

(c) Tenon-mortise joint

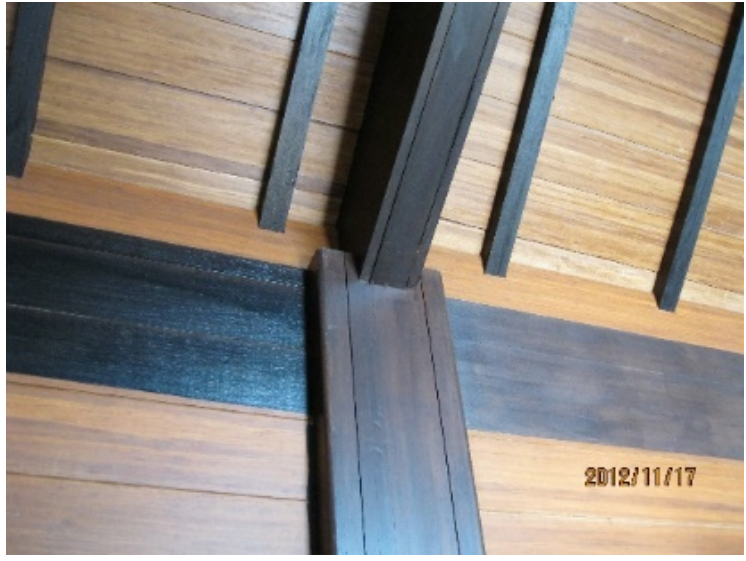

(b) Tenon-mortise joint

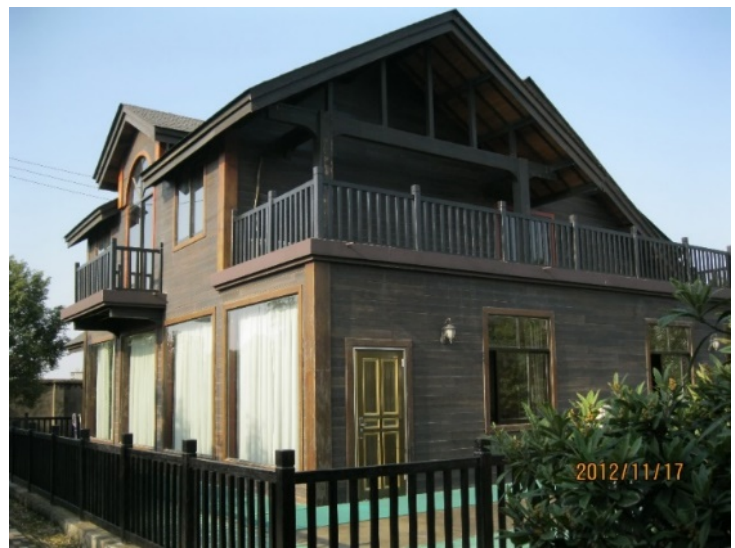

(d) PBSL villa

Figure 21: PBSL villa in Fengxin County (Built in 2008, reproduced with permission of Haitao Li) 
Figure 22: A tenon-mortise joint sample made of LBL (reproduced with permission of Haitao Li)

Figure 18 displays the construction process of the 'Lotus Pavilion' made of LBL in Jinggangshan City, China, which was constructed by Ganzhou Sentai bamboo company LTD. Figure 19 displays the construction process of office building made of LBL in Ganzhou City, China, which was constructed by Ganzhou Sentai bamboo company LTD. Figure 20 displays the joint details of earthquake-resistant bamboo villa made of PBSL in Nanjing Forestry University, which was built by the research team led by Academician Zhang Qisheng of Nanjing Forestry University and Academician Lv Zhitao of Southeast University. From above, it can be drawn that the joint configuration of engineered bamboo structure is similar to that of timber structure, and specific configuration of joint can help create more structural and spatial types to meet the practical and artistic requirements of modern architecture. Figure 21 displays the joint details of a PBSL villa in Fengxin County, China, which was constructed by Jiangxi Feiyu Bamboo Stock Co. LTD. Figure 22 is a tenon-mortise joint sample made of LBL.

In summary, many attempts have been made on the application of engineered bamboo in construction. From the existing engineering examples, no matter from the perspective of aesthetic appearance, environmental interest and economic benefits, engineered bamboo has more space for development in the future. However, many enterprises produce engineered bamboo only on the basis of experience without general standards, which leads to differences in material properties of different enterprises and even different batches. Therefore, academia, industry and policymakers must improve their collaboration and communication to make the standardization of structural bamboo products and bamboo-based products be smooth [65].

\section{Conclusion}

Since the beginning of the 21 st century, the world has paid significant attention to the sustainable development of the construction industry. Bamboo, as a green and renewable building material, provides the buildings with the characteristics of energy-saving and environmentally friendly. Additionally, the excellence in seismic performance, assembly performance and livability of bamboo has the potential to promotes its application in engineering construction to a wider range. With the rise of modern bamboo structure, scholars have carried out significant research on the manufacturing technology, physical and mechanical properties of engineered bamboo, but research on connection behavior is far from enough.

1. The physical and mechanical properties of materials in the connector need to be uniform and stable. However, many enterprises produce engineered bamboo only on the basis of experience without general standards, which leads to differences in material properties of different enterprises and even different batches. Therefore, formal general standards for manufacturing need to be developed in the future. 
2. The mechanical property of bolted joints is very complex. Scholars have considered many impact factors such as flexural strength of bolts, the embedding strength of members, specific gravity, bolt diameter, end distance, edge distance, loading direction, moisture content, grain direction, external temperature et al. However, it is still not enough. More influence factors like the permutation of bolts, working situations need to be considered deeply. Besides, the existing conclusion has yet to prove its universality.

3. Most of the existing studies just follow the codes and standards for timber structure, and make corresponding adjustments and improvements through regression and fitting method. The stress mechanism of the existing connection forms is not clear enough. Although engineered bamboo structures are analogous to timber structures, it is necessary to conduct a large number of experiments and theoretical studies to establish a unified design theory and calculation system that conform to the characteristics of engineered bamboo materials.

4. The current research on carpentry joints is mainly aimed at bamboo furniture. Nevertheless, some application of carpentry joints in engineered bamboo buildings has existed. At present, there is a lack of research on carpentry joints for utility in bamboo building structures. Thus, more research in this aspect should be carried out.

Acknowledgment: The research work presented in this paper is supported by the Natural Science Foundation of Jiang-su Province (No. BK20181402), the National Natural Science Foundation of China (51878354), National Key R\&D Program of China, the Open Fund Project from Key Laboratory of Concrete and Pre-stressed Concrete Structure of Ministry of Education (Southeast university), the China Postdoctoral Science Foundation (2015M580382), Jiangsu Postdoctoral Science Foundation Project (1501037A), Qing Lan Project, and a Project Funded by the Priority Academic Program Development of Jiangsu Higher Education Institutions. Any research results expressed in this paper are those of the writer(s) and do not necessarily reflect the views of the foundations.

\section{References}

1. Y. J. Li, B. Xu, Q. S. Zhang, S. X. Jiang, Present situation and the countermeasure analysis of bamboo timber processing industry in China, Journal of Forestry Engineering 1 (1) (2016) 2-7.

2. C. K. Hong, H. T. Li, R. Lorenzo, G. Wu, I. Corbi, O. Corbi, D. D. Wei, C. G. Yuan, D. Yang, H. Z. Zhang. Review on Connections for Original Bamboo Structures, Journal of Renewable Materials 7 (8) (2019) 713-730.

3. R. Lorenzo, L. Mimendi, M. Godina, H. T. Li, Digital analysis of the geometric variability of Guadua, Moso and Oldhamii bamboo, Construction and Building Materials 236 (2020) 117535.

4. M. X. Huang, X. C. Zhang, W. J. Yu, W. Z. Li, X. M. Liu, Mechanical properties and structure characterization of bamboo softened by high temperature steam, Journal of Forestry Engineering 1 (4) (2016) 64-68.

5. W. He, J. G. Song, T. Wang, J. S. Li, L. X. Xie, Effect of heat oil treatment on bamboo scrimber properties, Journal of Forestry Engineering 2 (5) (2017) 15-19.

6. B. H. Fei, R. Liu, X. M. Liu, X. F. Chen, S. Q Zhang, A review of structure and characterization methods of bamboo pits, Journal of Forestry Engineering. 4 (2) (2019) 13-18.

7. M. Mahdavi, P. L. Clouston, S. R. Arwade, Development of laminated bamboo lumber: review of processing, performance, and economical considerations, Journal of Materials in Civil Engineering 23 (7) (2011) 1036-1042.

8. H. T. Li, R. Liu, R. Lorenzo, G. Wu, L. B. Wang, Eccentric compression properties of laminated bamboo columns with different slenderness ratios, Proceedings of the Institution of Civil Engineers-Structures and Buildings 172 (5) (2019) 315-326. 
9. G. Chen, T. Zhou, C. L. Li, Q. S. Zhang, H. T. Li, Experimental study on the OSB webbed bamboo beams, Journal of Nanjing Forestry University (Natural Science Edition) 40 (05) (2016) 121-125.

10. H. T. Li, G. Wu, Z. H. Xiong, I. Corbi, O. Corbi, X. H. Xiong, H. Z. Zhang, Z. Y. Qiu, Length and orientation direction effect on static bending properties of laminated Moso bamboo, European Journal of Wood and Wood Products 77 (4) (2019) 547-557.

11. A. Sinha, D. Way, S. Mlasko, Structural Performance of Glued Laminated Bamboo Beams, Journal of Structural Engineering, 140 (1) (2014) 04013021.

12. H. T. Li, G. Wu, Q. S. Zhang, A. J. Deeks, J. W. Su, Ultimate bending capacity evaluation of laminated bamboo lumber beams, Construction and Building Materials 160 (2018) 365-375.

13. J. F. Correal, F. Ramirez, Adhesive bond performance in glue line shear and bending for glued laminated guadua bamboo, Journal of Tropical Forest Science 22 (4) (2010) 433-439.

14. H. T. Li, G. Wu, Q. S. Zhang, J. W. Su, Mechanical evaluation for laminated bamboo lumber along two eccentric compression directions, Journal of wood science 62 (6) (2016) 503-517.

15. Y. Xiao, Z. Li, Y. Wu, B. Shan, Research and engineering application progress of laminated bamboo structure, Building Structure 48 (10) (2018) 84-88.

16. Y. Xiao, B. Shan, GluBam Structures, China Architecture \& Building Press, China, 2013.

17. Q. Peng, Research on mechanical behavior of metal-plate-connected GluBam floor trusses, Hunan University, Changsha City, China, 2017.

18. H. T. Li, Z. Y. Qiu, G.Wu, D. D. Wei, R. Lorenzo, C. G. Yuan, H. Z. Zhang, R. Liu, Compression Behaviors of Parallel Bamboo Strand Lumber Under Static Loading, Journal of Renewable Materials 7 (7) (2019) 583-600.

19. H. Z. Zhang, H. T. Li, I. Corbi, O. Corbi, G. Wu, C. J. Zhao, T. W. Cao, AFRP influence on parallel bamboo strand lumber beams, Sensors 18 (9) (2018) 2854.

20. H. T. Li, Z. Y. Qiu, G. Wu, O. Corbi, D. D. Wei, L. B. Wang, I. Corbi, C. G. Yuan, Slenderness Ratio Effect on Eccentric Compression Properties of Parallel Bamboo Strand Lumber Columns, Journal of Structural Engineering 145 (8) (2019) 04019077.

21. Y. Wei, G. Wu, Q. S. Zhang, S. X. Jiang, Theoretical analysis and experimental test of full-scale bamboo scrimber flexural components, Journal of Civil, Architectural \& Environmental Engineering 34 (2012) 140-145.

22. H. T. Li, J. W. Su, A. J. Deeks, Q. S. Zhang, D. D. Wei, C. G. Yuan, Eccentric compression performance of parallel bamboo strand lumber columns, BioResources 10 (4) (2015) 7065-7080.

23. Y. X. Huang, Y. H. Ji, W. J. Yu, Development of bamboo scrimber: a literature review, Journal of Wood Science 65 (1) (2019) 25.

24. Y. L. Yu, R. Liu, Y. X. Huang, F. D. Meng, W. Yu, Preparation, physical, mechanical, and interfacial morphological properties of engineered bamboo scrimber, Construction and Building Materials 157 (2017) 1032-1039.

25. N. Q. Zhou, G. Q. Zhang, D. S. Huang, S. X. Jiang, Q. S. Zhang, Examination of dynamic characteristics of new bamboo structure by impact hammer test, Journal of Forestry Engineering 4 (2) (2019) 54-60.

26. H. T. Li, H. Z. Zhang, Z. Y. Qiu, J. W. Su, D. D. Wei, R. Lorenzo, C. G. Yuan, H. Z. Liu, C. G. Zhou, Mechanical properties and stress strain relationship models for bamboo scrimber, Journal of Renewable Materials 8 (1) (2020) 13-27. 
27. X. Li, M. Ashraf, H. T. Li, X. Y. Zheng, S. AI-Deen, H. X. Wang, P. J. Hazell, Experimental study on the deformation and failure mechanism of Parallel Bamboo Strand Lumber under drop-weight penetration impact, Construction and Building Materials 242 (2020) 118135.

28. C. Tan, H. T. Li, D. D. Wei, R. Lorenzo, C. G. Yuan, Mechanical Performance of Parallel Bamboo Strand Lumber Columns under Axial Compression: Experimental and Numerical Investigation, Construction and Building Materials 231 (2020) 117168.

29. X. Li, M. Ashraf, H. T. Li, X. Y. Zheng, H. X. Wang, S. AI-Deen, P. J. Hazell, An experimental investigation on Parallel Bamboo Strand Lumber specimens under quasi static and impact loading, Construction and Building Materials 228 (2020) 116724.

30. B. Sharma, A. Gatóo, M. Bock, M. Ramage, Engineered bamboo for structural applications, Construction and Building Materials 81 (2015) 66-73.

31. A. Lokaj, K. Klajmonová, Round timber bolted joints exposed to static and dynamic loading, Wood research 59 (3) (2014) 439-448.

32. E. M. Meghlat, M. Oudjene, H. Ait-Aider, J. L. Batoz, A new approach to model nailed and screwed timber joints using the finite element method, Construction and Building Materials 41 (2013) 263-269.

33. X. Z. Li, Y. Zhong, H. Q. Ren, Review on Performance and Impact Factors of Bolted Connection in Modern Wood Structure, World Forestry Research 25 (4) (2012) 52-57.

34. R. J. Ross, Wood handbook: wood as an engineering material, USDA Forest Service, Forest Products Laboratory, General Technical Report FPL-GTR-190, 2010.

35. G. W. Trayer, The bearing strength of wood under bolts, US Dept of Agriculture, Washington DC, 1932.

36. K. W. Johansen, Theory of timber connections, International Association for Bridge and Structural Engineering 9 (1949) 249-262.

37. T. E. McLain, S. Thangjitham, Bolted wood-joint yield model, Journal of Structural Engineering 109 (8) (1983) 1820-1835.

38. L. A. Soltis, F. K. Hubbard, T. L. Wilkinson, Bearing strength of bolted timber joints, Journal of Structural Engineering 112 (9) (1986) 2141-2154.

39. I. G. L. B. Eratodi, A. Triwiyono, A. Awaludin, T. A. Prayitno, The Effect of Specific Gravity on Embedding Strength of Glued-laminated (glulam) Bamboo: Numerical Analysis and Experiment, ASEAN Engineering Journal Part C 3 (1) (2012) 30-40.

40. F. Ramirez, J. F. Correal, L. E. Yamin, J. C. Atoche, C. M. Piscal, Dowel-bearing strength behavior of glued laminated Guadua bamboo, Journal of Materials in Civil Engineering 24 (11) (2012) 1378-1387.

41. G. E. Gonzalez Beltran, Determination of the embedding strength of plybamboo. Report TUE-BCO-01-03, Eindhoven University of Technology, Netherlands, 2000.

42. X. Z. Li, Research on Bearing Performance of Bolt Joint for Recombinant Bamboo, Chinese Academy of Forestry, Beijing, China, 2013.

43. X. Z. Li, Y. Zhong, H. Q. Ren, Calculation Formula for Dowel Bearing Strength Parallel to Grain in New-type Engineered Bamboo Products, Journal of Civil, Architectural \& Environmental Engineering 35 (s1) (2013) 4-8.

44. J. W. Zhou, D. S. Huang, F. H. Zhao, Experimental study on dowel-compression strength of parallel bamboo strand lumber, Building Structure 45 (22) (2015) 107-110.

45. J. W. Zhou, D. S. Huang, Y. Song, C. Ni, Experimental Investigation on Embedding Strength Perpendicular to Grain of Parallel Strand Bamboo, Advances in Materials Science and Engineering 2018 (2018). 
46. Z. Y. Cui, F. Wang, M. Xu, Z. F. Chen, Experimental study on embedding strength of bamboo scrimber parallel to grain at high temperatures, Journal of Southeast University (Natural Science Edition) 47 (06) (2017) 11741179.

47. S. Y. Tang, Experimental Research on Embedding Strength of Parallel Strand Bamboo (PSB), Technology Development of Enterprise 36 (09) (2017) 66-67+96.

48. N. Khoshbakht, P. L. Clouston, S. R. Arwade, A. C. Schreyer, Computational modeling of laminated veneer bamboo dowel connections, Journal of Materials in Civil Engineering 30 (2) (2017) 04017285.

49. N. Khoshbakht, P. L. Clouston, S. R. Arwade, A. C. Schreyer, Evaluation of ASTM D5764 dowel connection tests for laminated veneer bamboo (LVB), Journal of Testing and Evaluation 47 (4) (2019).

50. D. S. Zhang, B. H. Fei, H. Q. Ren, Z. Wang, The research of joint composed by laminated bamboo lumber, in: Modern Bamboo Structures: Proceedings of the First International Conference , 2008.

51. Y. Zhong, H. Q. Ren, J. Z. Zhang, X. Z. Li, W. T. Xu, Compression Performance of Bolted Connection with Metal Plates for Laminated Bamboo Board, Journal of Building Materials 16 (04) (2013) 642-648.

52. R. Z. Yang, Research and application of glubam mechanical property and property of bolted joints, Hunan University, Changsha City, China, 2009.

53. R. Z. Yang, Research on material properties of Glubam and its application, Hunan University, Changsha City, China, 2013.

54. L. Feng, Bolt connection of modern bamboo-wood structures theoretical analysis and experimental study, Hunan University, Changsha City, China, 2015.

55. A. P. Zhou, D. S. Huang, S. Y. Tang, S. Y. Zhao, Experimental research on bearing capacity of the bolted PSBsteel-PSB joint, Journal of Nanjing Tech University (Natural Science Edition) 38 (5) (2016) 34-39.

56. J. J. B. Debije, Dowel type connections in laminated bamboo with multiple slotted-in steel plates, Technische Universiteit Delft, Netherlands, 2016.

57. L. Dai, Study on the performance of bolt connection of Strand Woven Bamboo Lumber used in outdoor furniture, Zhejiang A\&F University, Hangzhou City, China, 2016.

58. F. Wang, Experimental research on the fire performance of bolted connection in parallel strand bamboo, Southeast University, Nanjing, China, 2016.

59. T. Reynolds, B. Sharma, K. Harries, M. Ramage, Dowelled structural connections in laminated bamboo and timber, Composites Part B: Engineering 90 (2016) 232-240.

60. X. Qin, Research on Performance of Hardware Connection on Corner Joint of Bamboo Glulam Furniture, Nanjing Forestry University, Nanjing, China, 2017.

61. J. W. Zhou, D. S. Huang, C. Ni, Y. R. Shen, L. L. Zhao, Experiment on Behavior of a New Connector Used in Bamboo (Timber) Frame Structure under Cyclic Loading, Advances in Materials Science and Engineering (2018).

62. Z. R. Huang, D. S. Huang, Y. H. Wang, Y. Feng, Cyclic Behavior of a Bamboo-Steel Hybrid Moment Frame with a Novel Energy Dissipation Connection, Modular and Offsite Construction (MOC) Summit Proceedings (2019) 429-436.

63. G. Tang, L. F. Yin, Z. J. Li, Y. Li, L. G. You, Structural behaviors of bolted connections using laminated bamboo and steel plates, Structures 20 (2019) 324-339.

64. W. F. Zhang, S. H. Gu, C. C. Wang, H. T. Cheng, G. Wang, Physico-Mechanical and Joint Performance of Bamboo Veneer Products Manufactured by Mould Pressing, BioResources 14 (2) (2019) 3823-3832. 
65. A. Gatóo, B. Sharma, M. Bock, H. Mulligan, M. H. Ramage, Sustainable structures: bamboo standards and building codes, Proceedings of the Institution of Civil Engineers-Engineering Sustainability 167 (5) (2014) 189196.

66. M. J. He, J. Zhang, Z. Li, M. L. Li, Production and mechanical performance of scrimber composite manufactured from poplar wood for structural applications, Journal of wood science 62 (5) (2016) 429-440.

67. Z. Shu, Z. Li, X. Yu, J. Zhang, M. J. He, Rotational performance of glulam bolted joints: Experimental investigation and analytical approach, Construction and Building Materials 213 (2019) 675-695.

68. L. Zhang, W. Liu, L. Wang, Z. Ling, Mechanical behavior and damage monitoring of pultruded wood-cored GFRP sandwich components, Composite Structures 215 (2019) 502-520.

69. Z. Gao, Y. Cao, Y. Wang, Z. Wang, Measurements of the Shear Modulus of Materials by the Free-Plate Torsional Mode Shape Method, Journal of Testing and Evaluation 47 (2) (2018) 1163-1181.

70. Z. Wang, W. Xie, Z. Wang, Y. Cao, Strain method for synchronous dynamic measurement of elastic, shear modulus and Poisson's ratio of wood and wood composites, Construction and Building Materials 182 (2018) 608-619.

71. Y. Z. Erdil, A. Kasal, C. A. Eckelman, Bending moment capacity of rectangular mortise and tenon furniture joints, Forest Products Journal 55 (12) (2005) 209.

72. J. Q. Li, Studies on new-type glued laminated bamboo furniture, Nanjing Forestry University, Nanjing, China, 2005.

73. Q. Xu, The Study on Joint Property of Oval-tenon of the Glued Laminated Bamboo, Nanjing Forestry University, Nanjing, China, 2008.

74. S. Y. Huang, A study on the design of new-sino-style furniture made of recombinant bamboo, Nanjing Forestry University, Nanjing, China, 2011.

75. J. Q. Li, L. H. Chen, T. Su, Study on bolt joint intensity of laminated bamboo for furniture, Journal of Fujian College of Forestry. 31 (3) (2011) 271-275.

76. H. W. Zhang, Study on the Optimize Design for Parameters of Screw Thread Used in Glued Laminated Bamboo and the Mechanical Property, Nanjing Forestry University, Nanjing, China, 2012.

77. Y. Chen, S. Zhu, Y. Guo, S. Liu, D. Tu, H. Fan, Investigation on withdrawal resistance of screws in reconstituted bamboo lumber, Wood Research 61 (5) (2016) 799-810.

78. A. Sinha, B. T. Miyamoto, Lateral load carrying capacity of laminated bamboo lumber and oriented strand board connections, Journal of Materials in Civil Engineering 26 (4) (2013) 741-747.

79. J. M. Wu, Test research on ultimate strength of metal-plate-connected G1uBam joints, Hunan University, Changsha City, China, 2016. 